This PDF is a selection from a published volume from the National Bureau of Economic Research

Volume Title: Innovation Policy and the Economy, Volume 2

Volume Author/Editor: Adam B. Jaffe, Josh Lerner and Scott Stern, editors

Volume Publisher: MIT Press

Volume ISBN: 0-262-60045-5

Volume URL: http://www.nber.org/books/jaff02-1

Conference Date: April 17, 2001

Publication Date: January 2002

Title: Government Support for Commercial R\&D:

Lessons from the Israeli Experience

Author: Manuel Trajtenberg

URL: http://www.nber.org/chapters/c10786 


\title{
Government Support for Commercial R\&D: Lessons from the Israeli Experience
}

\author{
Manuel Trajtenberg, Tel Aviv University, NBER, and CIAR
}

\section{Executive Summary}

Israel constitutes an interesting "laboratory case" of government intervention in the realm of R\&D policy. The recognized scientific and technological prowess of the country was leveraged by extensive government support for commercial $R \& D$ projects. $R \& D$ policies proved to be highly responsive to changing circumstances, instituting innovative programs such as a government-sponsored fund that jump-started the venture capital market, the technological Incubators program, a program for the support of generic projects conducted by consortia of firms and academia, etc. The Israeli high-tech sector has grown remarkably fast since the mid-1980s, and it is quite likely that government policies significantly contributed to its success. In this paper we review in detail these policies as well as the challenges that confront them: the design of alternative allocation schemes for $R \& D$ grants in view of a rigid budget constraint, possible ways of departing from neutrality, the conditionality of production in Israel, the difficulties in setting a policy target for R\&D spending, etc. We also lay out the more general issues and possible lessons for other countries that arise from the Israeli case: what should be the policy goal in terms of total resources devoted to $R \& D$, to what extent these policies should target supply vs. demand in the market for $R \& D$ inputs, which types of support one can envision in the context of R\&D policies, and how these may be affected by international spillovers.

\section{Introduction ${ }^{1}$}

Interest in $R \& D$ policy as an area of research has experienced recently a marked upsurge within mainstream economics. ${ }^{2}$ This probably reflects the perception that technical advances in information technologies (IT) and related areas have been having a noticeable and sustained effect on productivity growth in recent years (contrary to the previous uneasiness in that respect vividly articulated in "Solow's paradox"). Since R\&D is driving the relentless flow of innovations that fuel IT and the "new 
economy," policies that affect R\&D have thus become an attractive field of inquiry. Moreover, advanced economies all over the world see it as a major goal to partake in the processes associated with the current wave of innovations, and therefore their interest in R\&D policy is immediate and pragmatic.

Israel constitutes an interesting "laboratory case" of government intervention in the realm of R\&D policy. The recognized potential of the country in scientific and technological prowess was leveraged by extensive government support for commercial R\&D projects. The principle of neutrality that governs the main support programs ensured that resources allocated responded to market signals rather than to bureaucratic directives. The Office of the Chief Scientist (OCS) of the Ministry of Industry and Trade, the main conduit of R\&D policies in Israel, proved to be highly responsive to changing circumstances, instituting a series of innovative programs beyond the regular matching $R \& D$ grants (which still constitute the bulk of the support): "Yozma," the government-sponsored venture capital fund that jump-started the now thriving venture capital market in Israel (and soon after terminated its activities); the "Incubators" program, which responded to the opportunities opened up by the mass immigration of scientists and skilled workers from the Soviet Union; the "Magnet" program, designed to support generic, precompetitive projects conducted by consortia of firms and academia; etc.

And, indeed, the high-tech sector in Israel has flourished and grown remarkably fast since the mid-1980s. Thus, for example, the number of U.S. patents granted to Israeli inventors has more than tripled since 1985, Israeli high-tech exports grew eightfold in the past decade, etc. Even if still tentative, available evidence suggests that government policies contributed significantly to this success in various ways, including the vast expansion of capital markets, a positive effect of government grants on productivity growth, and the further stimulation of R\&D spending (i.e., additionality).

However, the very success of the high-tech sector and presumably of the underlying policies pose new challenges: a rigid cap on the subsidies budget imposed in the late 1990s brought into sharp focus the question of how to allocate scarce funds to a much larger pool of support applications. Options include instituting a competitive ranking system, randomization, and departures from neutrality. Still, the more fundamental issue is that of setting a target $\mathrm{R} \& \mathrm{D} / \mathrm{GDP}$ ratio, and deriving from it the optimal level of total R\&D support. The rapid growth 
of the R\&D sector eventually ran into a highly inelastic segment of the supply of qualified manpower, inflating wages for R\&D personnel, and thus restraining the actual growth of innovational efforts. Clearly, government policies will have to address both sides of the market for R\&D inputs if they are to be effective. Further open issues include the payback provision, the requirement of production in Israel, and the extent to which support should be aimed at more generic research.

It seems that the key to the apparent success of R\&D policies in Israel has been both the willingness of the government to take substantial risks in allocating resources, and a remarkable extent of flexibility and creativity in responding to rapidly changing needs. ${ }^{3}$ In order to be effective, R\&D policy ought to mirror the sector to which it is aimed-risktaking and innovativeness are after all the hallmarks of high tech. Government programs in this area should learn first and foremost from their "clients" (without being coopted by them), rather than from more traditional realms of policy. Given the inherent dynamism of the high-tech sector, any policy that follows rigid rules is bound to rapidly become either ineffective and/or inefficient. Much of this is of potential relevance for the U.S., as well as for other countries seeking an active role for government in the realm of advanced technology and innovation.

This paper provides the basic ingredients for the understanding of R\&D policy in Israel, and tries to draw from it wider lessons pertinent to the design of R\&D policy in general. Section II is primarily descriptive: it opens with a review of the Office of the Chief Scientist (OCS) main programs; the third subsection dwells on the Yozma venture capital program, and the fourth presents quantitative indicators of OCS activities over time, followed in the fifth by a review of studies on the contribution of the OCS, and an overview of the rise of the high-tech sector in Israel with the help of patent data. Section III discusses in detail the main policy issues that arise in this context: alternative allocation schemes for R\&D grants, possible ways of departing from neutrality, the conditionality of production in Israel, the desirability of supporting Magnet consortia vs. regular R\&D projects, the difficulties in setting a policy target for R\&D spending, etc.

Section IV lays out the more general issues and possible lessons for other countries that arise from a close-up examination of the Israeli case. Israel experimented, in a short period of time and with great intensity, with a variety of potent policy schemes and mechanisms. Thus, the consequences of such policies, both beneficial and harmful, 
are more salient and hence lend themselves more easily to object lessons in policy design. We group these issues into the following categories: (1) what should be the policy goal in terms of the total resources devoted to R\&D; (2) supply vs. demand, i.e. to what extent the policies should target either side of the market (for R\&D inputs); (3) which types of support one can envision in the context of R\&D policies; (4) which sort of mechanisms should be considered for implementing such policies; and (5) how should we think of R\&D support in view of international spillovers. Finally, Section $V$ offers some closing remarks.

\section{Government Support for Industrial R\&D in Israel: An Overview $^{4}$}

\section{Background}

The beginning of government support for industrial (civilian) R\&D in Israel dates back to 1968: a government commission, headed by Prof. Kachalsky, recommended the creation of the Office of the Chief Scientist (OCS) at the Ministry of Industry and Commerce, with the mandate to subsidize commercial R\&D projects undertaken by private firms. Support was confined until then to National R\&D Labs, and to academic $R \& D$, in addition to the weighty resources that were devoted to defense-related R\&D and to agricultural research. And indeed, industrial $R \& D$ rose rapidly following the establishment of the OCS. Between 1969 and 1987 industrial R\&D expenditures grew at $14 \%$ per year, and high-tech exports grew from a mere $\$ 422$ million in 1969 (in 1987 dollars), to $\$ 3316$ million in 1987 (Toren 1990).

The next key development was the passing of the Law for the Encouragement of Industrial R\&D in 1985 (it has been revised several times since). This is the main piece of legislation that has defined the parameters of government policy towards industrial R\&D ever since. The stated goals of the legislation, to be implemented by the OCS, are to develop science-based, export-oriented industries, which will promote employment and improve the balance of payments. In order to do this, the legislation was supposed to provide the means to expand and exploit the country's technological and scientific infrastructure, and leverage its high-skilled human resources. The 1985 law may soon undergo a significant revision, in view of the changes undergone by the high-tech sector in the course of the last decade and the budgetary re- 
straint of the late 1990s, which has resulted in excess demand for R\&D grants under the present system.

At the heart of the law is a program of financial incentives. Companies-whether big corporations or small startups-which meet certain eligibility criteria are entitled to receive matching funds for the development of innovative, export-targeted products. The OCS funds up to $50 \%$ of R\&D expenses in established companies, and up to $66 \%$ for startups. The OCS supports and administers a wide range of additional programs, the main ones being: (1) Magnet, a program to encourage precompetitive generic research conducted by consortia; (2) a program of technological incubators; (3) various programs involving bilateral and multilateral international $R \& D$ collaboration. We review these programs here in some detail, and present quantitative indicators of their performance.

\section{A Review of OCS Programs 5}

Support for Standard RED Programs This is by far the largest program, and administering it constitutes the main activity of the OCS. The way it works is as follows. Qualifying firms submit grant applications for specific R\&D projects; these are reviewed by a Research Committee, and if they are approved (about $70 \%$ are), the applicants receive a grant of up to $50 \%$ of the stated R\&D budget for the project. Successful projects (i.e. those leading to sales) are required to repay the grant, by paying back to the OCS royalties of $3 \%$ of annual sales, ${ }^{6}$ up to the dollar-linked amount of the grant. Recipients of the R\&D grants have to abide by the following conditions: (1) the R\&D project must be executed by the applicant firm itself; (2) the product(s) that emerge from the R\&D project must be manufactured in Israel; (3) know-how acquired in the course of the R\&D may not be transferred to third parties. $^{\text {? }}$

The Research Committee, chaired by the Chief Scientist, is responsible for defining the conditions for granting aid (within the confines of the 1985 law), and for reviewing the applications and selecting the recipients. The committee is staffed both by qualified government officials and by public representatives, but it relies on (outside) professional referees and advisers to review the applications. Decisions of the Research Committee can be appealed before an Appeals Committee.

Grants of (up to) $50 \%$ of the total R\&D costs are given to projects that "lead to know-how, processes or systems for manufacturing a new 
product/process or substantially improving existing ones." ${ }^{8}$ Products aimed at the military (export) market qualify for grants of up to $30 \%$. Grants covering $30 \%$ of R\&D costs are available for projects leading to improvements in existing civilian products, and $20 \%$ for improvements of military (export) products. Startup companies qualify for grants of up to $2 / 3$ of $R \& D$ costs, with a ceiling of $\$ 250,000$ a year for two years.

Israel has a long-standing policy of encouraging the development of an industrial base in peripheral areas (away from the main urban centers), which is reflected also in the R\&D support programs. Thus, $R \& D$ projects performed in the preferential peripheral areas ("Grade A Development Areas") are entitled to additional $10 \%$ grants: for civilian projects that means grants of up to $60 \%$ (rather than $50 \%$ for the others), and military projects are entitled to grants of up to $40 \%$ (rather than $30 \%$ for the others).

The Magnet Program Notwithstanding the rapid growth of the high-tech sector in Israel from the late 1960s onwards, it became clear by the early 1990s that the industrial landscape in Israel was rather fragmented and, with few notable exceptions, that Israeli industrial companies were too small to be able to meet the escalating costs of developing new technologies in cutting edge fields. Moreover, Israel boosted world-class research universities, but they operated largely in isolation from surrounding industrial developments and needs, and hence the vast economic potential embedded both in the highly qualified academic manpower and in university research remained largely untapped. ${ }^{9}$

Against this background the OCS established in 1993 the Magnet program, $^{10}$ to support the formation of consortia made of industrial firms and academic institutions in order to develop generic, precompetitive technologies. ${ }^{11}$ These consortia are entitled to multiyear R\&D support (usually 3 to 5 years), consisting of grants of $66 \%$ of the total approved $\mathrm{R} \& \mathrm{D}$ budget, with no recoupment requirements. The consortia must comprise the widest possible group of industrial members operating in the field, ${ }^{12}$ together with Israeli academic institutions doing research in scientific areas relevant to the technological goals of the consortia.

Mindful of possible conflict with antitrust provisions, consortium members must pledge to make the products or services resulting from the joint project available to any interested local party, at prices that do not reflect the exercise of monopoly power. Keeping with the mandate 
to encourage precompetitive technologies, support to the consortium ceases once the equivalent of the pilot plant stage is reached. That is, the additional $R \& D$ required for the actual commercialization of the products is not supported by Magnet, but the member companies may then apply for regular grants from the OCS. Contrary to the regular OCS support to industrial R\&D projects, the Magnet program operates on a competitive basis, that is, it is open to any number of proposals for the formation of new consortia, and it selects only those that merit support on the basis of a ranking system.

By the end of 1999 there were 18 consortia in operation, commanding a budget of about $\$ 60$ million, and four additional consortia in various stages of gestation. These consortia span a wide range of technologies, primarily in communications, microelectronics, biotechnology, and energy. They include ground stations for satellite communications, digital wireless communications, magnesium technologies, DNA markers, 0.25-micron devices, digital printing, etc.

The Incubators Program ${ }^{13}$ Technological incubators are support organizations that give fledgling entrepreneurs an opportunity to develop their innovative technological ideas and set up new businesses in order to commercialize them. The program was introduced in the early 1990s, when immigration from the former Soviet Union had reached its peak. Many of these immigrants were scientists and skilled professionals who came to Israel with highly valuable human capital as well as with plenty of ideas for innovative products. However, they were lacking in virtually all other dimensions required for commercial success, from knowledge of the relevant languages (e.g. Hebrew and English) and of commercial practices in western economies, to managerial skills and access to capital. Even though it targeted new immigrants, the program is open to all.

The goal of the incubators is thus to support novice entrepreneurs at the earliest stage of technological entrepreneurship, and help them implement their ideas and form new business ventures. The premise is that the technological incubator would significantly enhance the entrepreneur's prospects of raising further capital, finding strategic partners, and emerging from the incubator with businesses that can stand on their own. Of course, this initial stage is the riskiest, and certainly in the early 1990s there were virtually no other sources of finance in Israel for such ventures. Since the mid-1990s there has been a growing influx of venture capital, and hence it may well be that the purely risk-sharing 
function undertaken by this program may be less critical at present than it was at its inception.

Each incubator is structured so as to handle 10-15 projects simultaneously, and provides assistance in the following areas: determining the technological and marketing applicability of the idea, drawing up an R\&D plan and organizing the R\&D team, raising capital and preparing for marketing, provision of secretarial and administrative services, maintenance, procurements, accounting, and legal advice. ${ }^{14}$

To qualify, projects must be aimed at developing an innovative idea with export potential. The R\&D team is to be made of three to six workers, and the stay at the incubator is up to two years. The expectation is that by the end of the period there will be a prototype and an orderly business plan, and the project will be ready for further commercial investment and/or the involvement of a strategic partner. The budget for each project is about $\$ 150,000$ per year, for two years at most. ${ }^{15}$ As with the regular OCS program, the ensuing products have to be manufactured in Israel, and if successful the entrepreneur has to eventually repay the grant through royalties on sales.

Since its inception in 1991 and up to the end of 1998, the incubators have managed close to 700 projects, of which about 200 were still running as of December 1998 in 27 incubators across the country. Current projects employ about 900 professionals, $70 \%$ of them recent immigrants, all with academic training and many with advanced degrees. Of the 500 "graduating" projects, the success rate was about $50 \%$, i.e., half managed to continue on their own, and the remaining half were discontinued. About 200 projects (out of the successful half) managed to attract additional investment, ranging from a mere $\$ 50,000$ to several million dollars. There are no predetermined technological areas for the submission of projects. The actual distribution of projects by fields has been as follows: electronics $27 \%$, software $20 \%$, medical instrumentation $17 \%$, chemistry 27 , miscellaneous $9 \%$.

International Cooperation The relative advantage of Israel's high-tech sector manifests itself primarily in its technological prowess in the R\&D stages. However, Israeli high-tech companies suffer from serious difficulties in marketing abroad, primarily because they are geographically distant from the target markets, and because they are small. Thus, cooperation with foreign companies active in the target markets is likely to increase the ability of Israeli technology and products to penetrate global markets. In that spirit, the Israeli government has signed in 
recent years a number of bilateral $R \& D$ cooperation agreements with foreign governments. These are meant to encourage contacts between Israeli and foreign companies leading to joint R\&D, manufacturing, and marketing. Foreign companies are expected to benefit by gaining access to advanced Israeli technology, and they are also likely to derive commercial advantages from Israel's simultaneous free trade agreements with the U.S. and the European Union (few countries enjoy both).

Joint ventures between Israeli and foreign companies, authorized by the relevant authorities in the respective countries, are entitled to aid from both governments according to the regulations prevailing in each. Bilateral agreements exist already with a number of countries, including the U.S., Canada, France, Holland, and Spain; their implementation is the responsibility of the Chief Scientist, assisted by The Israeli Industry Center for R\&D (MATIMOP).

The Israel-U.S. Binational Industrial Research and Development Foundation (BIRD) was founded in the early 1980s under a convention signed by both governments. Its objective was to promote and support joint, nondefense, industrial research and development activities of mutual benefit to the private sectors of the two countries. The Foundation has an independent legal status, and its main office is in Israel. Its Board of Governors is composed of representatives of the U.S. and Israeli governments.

BIRD participates in the funding of joint R\&D via conditional grants amounting to $50 \%$ of the project costs, up to a maximum of $\$ 1.5$ million per project. If a project succeeds, BIRD receives royalties-a pretax expense to the payer-up to a maximum of $150 \%$ of the conditional grant. Only in cases where a project fails and there are no sales are the companies exempted from repaying the grants. BIRD also helps Israeli or American companies identify partners in order to enable them to submit joint $R \& D$ programs for funding by the Foundation.

Additional Support Programs Beyond the main programs just described, the OCS offers a variety of additional assistance programs, aimed at specific stages of the innovation cycle or at particular segments in the progression from an innovative idea to a full-fledged commercial enterprise. Thus for example, the Bridging Aid program offers support for the transition between R\&D and manufacturing, including the construction of prototypes and the operation of pilot plants; another program supports studies of the market potential for new 
technologies, prior to the investment of large sums in the R\&D stage; etc. Although much smaller in budget, these programs may play an important role in making sure that potentially viable projects don't fall in between the cracks along the hazardous way towards successful commercial implementation.

\section{Jump-Starting the Venture Capital Market}

From the start, government support to $R \& D$ was meant not only to incentivize innovative activities, but also to compensate for the lack of well-developed capital markets. The Israeli stock exchange was a small operation up to the mid 1990s, and did not offer a significant channel for raising funds; foreign capital did flow in to some extent, but it took primarily the form of direct investments, not of liquid funds; Israeli savings were handled mostly by the concentrated banking sector, and in particular by highly regulated mutual and providence funds that invested primarily in government bonds. With few exceptions, the high-tech sector could not rely on local sources of finance and, given the impediments at the time, for the most part could not raise capital abroad either. Thus, the R\&D subsidies provided by the OCS fulfilled also an acute financial need, but they could hardly make up for the dearth of other financial sources. In addition, Israeli high-tech firms were traditionally strong in technology but lacking in managerial expertise and competencies.

Recognition of these needs brought the government to establish in 1992 the Yozma (meaning "initiative" in Hebrew) program, which was meant to jump-start the venture capital market in Israel. Yozma established a number of venture capital funds, that were initially funded by the government but that included also local and foreign private investors. The "carrot" offered to the latter was the issuing of options to buy Yozma's shares in these funds in 5 years' time at a predetermined price. Yozma managed to attract prominent foreign multinational investors (Advent of Boston, GAN of France, Daimler-Benz of Germany, the China Venture Management of Taiwan, etc.), which brought along not only their financial resources but most importantly their expertise. Shortly after its establishment, Yozma managed to set up 10 venture capital funds and helped raise close to $\$ 200$ million.

Contrary to other government programs, Yozma had at inception a fixed life expectancy of 7 years. In fact, though, its rapid success allowed it to terminate its activities early on: in 1997 its direct investment 
portfolio was privatized, and thus its mission came to an end. Since then the venture capital market in Israel has boomed, with over 80 funds in operation, having raised close to $\$ 5$ billion for hundreds of startups. In addition, capital markets have greatly expanded in Israel since the mid-1990s, and international access has improved dramatically. For example, Israel is the foreign country with the largest number of IPOs in Nasdaq (closely contested by Canada). This burst of funding sources imply that government support to $R \& D$ can confine itself to its original role of subsidizing innovation in order to bridge the gap between the social and the private rate of return, without having to take on a further financial role.

The case of Yozma is remarkable in that the government reacted quickly to a pressing need, and did so in a way that ensured a limited and transitory role for itself (with a "self-destruct" clock of 7 years). Yozma acted purely as a catalyst and marketmaker, in an area where surely governments have no comparative advantage. On the other hand, the government did not presume that the "invisible hand" will just do its job unaided, but took on the role of one-time entrepreneur to make it happen in a timely fashion.

\section{Quantitative Indicators of OCS Support Programs}

Systematic data on the OCS are hard to obtain, and in fact there are virtually no official statistics on the activities and budgets of the OCS since its creation in 1969. The lack of data has been detrimental to the functioning of the OCS and has surely impaired the formulation of R\&D policy at all levels. The OCS has long been aware of the problem, and efforts are being made to remedy it in a fundamental way. The data presented here are based on reports supplied to us by the OCS in January $2000,,^{16}$ but there still remain questions regarding some of the figures, and hence these should be seen as tentative data, which require further scrutiny.

Table $3.1^{17}$ shows the OCS budget since 1988, as well as paybacks, and the amounts allocated to the Magnet and Incubators programs. Total R\&D grants administered by the OCS increased steeply since 1988 and up to the mid-1990s, then increased slightly until 1997, and have changed little since. Paybacks rose very fast throughout the whole period,,$^{18}$ and in fact their weight in the OCS budget has increased dramatically from a mere $7 \%$ in 1988 to $32 \%$ by the late 1990 s. What this means is that about $1 / 3$ of the present OCS budget just constitutes "recycling" 
Table 3.1

The OCS Budget 1988-2000 (in current \$ million)

\begin{tabular}{|c|c|c|c|c|c|c|}
\hline Year & $\begin{array}{c}(1) \\
\text { R\&D } \\
\text { Grants }\end{array}$ & Paybacks & $\begin{array}{c}(3) \\
\text { Paybacks/ } \\
\text { Grants }\end{array}$ & $\begin{array}{c}\text { (4) } \\
\text { Net } \\
\text { Grants }^{\mathrm{a}}\end{array}$ & Magnet & $\begin{array}{c}\text { (6) } \\
\text { Incubators }\end{array}$ \\
\hline 1988 & 120 & 8 & 0.07 & 112 & - & - \\
\hline 1989 & 125 & 10 & 0.08 & 115 & - & - \\
\hline 1990 & 136 & 14 & 0.10 & 122 & - & - \\
\hline 1991 & 179 & 20 & 0.11 & 159 & 0.3 & 3.6 \\
\hline 1992 & 199 & 25 & 0.13 & 174 & 3.7 & 16 \\
\hline 1993 & 231 & 33 & 0.14 & 198 & 4.6 & 23 \\
\hline 1994 & 316 & 42 & 0.13 & 274 & 10 & 28 \\
\hline 1995 & 346 & 56 & 0.16 & 290 & 15 & 31 \\
\hline 1996 & 348 & 79 & 0.23 & 269 & 36 & 30 \\
\hline 1997 & 397 & 102 & 0.26 & 295 & 53 & 30 \\
\hline 1998 & 400 & 117 & 0.29 & 283 & 61 & 30 \\
\hline 1999 & 428 & 139 & 0.32 & 289 & 60 & 30 \\
\hline $2000^{b}$ & 395 & 128 & 0.32 & 267 & 70 & 30 \\
\hline
\end{tabular}

a R\&D grants minus paybacks.

${ }^{\mathrm{b}}$ Estimates.

of funds within the high-tech sector, and not government subsidy to R\&D. The net subsidy is given in column 4 under "Net grants": these peaked in 1995, and have since declined slightly (certainly more so in real terms). Furthermore, if we subtract the funds allocated to the Magnet and the Incubators programs, we can see that the net subsidy to the regular OCS grants program has declined very substantially since 1995 (by about $25 \%$ up to 1999 , in nominal terms).

The number of firms applying to the OCS for grants went from 450 in 1990 to about 600 in 1999, after reaching a peak of 777 in 1994. The decline since 1994 includes, quite surprisingly, startups that applied for the first time. ${ }^{19}$ Given the rapid growth in the overall number of startups throughout the economy, ${ }^{20}$ the decline in the number of first-time startup applicants may well reflect a change in their funding strategy, that is, more of them may prefer to rely on venture capital funds rather than on the OCS (without strings attached with regard to production in Israel or the eventual sale of the firm to foreign corporations). ${ }^{21}$ In the course of the 1990s a total of 2380 firms applied for support from the OCS for the first time. This is a large number by any standard, and offers further indication of the prominent role that the OCS has played in fostering the high-tech sector.

Tables 3.2-3.4 show the distribution of projects and grants by size of firms. ${ }^{22,23}$ The annual number of projects supported averaged 1300 for 
Table 3.2

Number of projects approved by size of firms

\begin{tabular}{lrrrr}
\hline & \multicolumn{3}{c}{ Number } \\
\cline { 2 - 4 } Year & \multicolumn{2}{c}{ Small and medium } \\
\cline { 3 - 4 } & Large & \multicolumn{1}{c}{ All } & Startups & \\
1995 & 219 & 1303 & 357 & Total \\
1996 & 212 & 1170 & 314 & 1522 \\
1997 & 207 & 1045 & 270 & 1382 \\
1998 & 266 & 1009 & 285 & 1252 \\
1999 & 202 & 960 & 245 & 1275 \\
Total & 1106 & 5487 & 1471 & 1162 \\
\hline
\end{tabular}

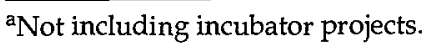

Table 3.3

Grants by size of firm

\begin{tabular}{lcccr}
\hline & \multicolumn{4}{c}{ Grants (millions of current \$) } \\
\cline { 2 - 4 } Year & \multicolumn{2}{c}{ Small and medium } \\
\cline { 2 - 4 } & Large & All & Startups & \\
1995 & 144 & 202 & 62 & Total \\
1996 & 149 & 199 & 66 & 346 \\
1997 & 161 & 236 & 67 & 348 \\
1998 & 157 & 243 & 60 & 397 \\
1999 & 99 & 329 & 68 & 400 \\
Total & 710 & 1209 & 323 & 428 \\
\hline
\end{tabular}

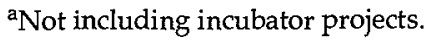

Table 3.4

Average grant per project by size of firm

\begin{tabular}{lcccc}
\hline & \multicolumn{4}{c}{ Average grant (thousands of current \$) } \\
\cline { 2 - 4 } Year & \multicolumn{4}{c}{ Small and medium } \\
\cline { 2 - 4 } & Large & All & Startups $^{\text {a }}$ & Overall mean \\
\hline 1995 & 658 & 322 & 174 & 227 \\
1996 & 703 & 366 & 210 & 252 \\
1997 & 778 & 466 & 248 & 317 \\
1998 & 590 & 463 & 211 & 314 \\
1999 & 490 & 643 & 278 & 368 \\
Mean & 642 & 440 & 220 & 291 \\
\hline
\end{tabular}

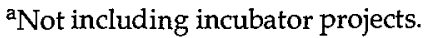


the past 5 years, declining from a high of 1500 in 1995 to 1200 in $1999 . .^{24}$ On the other hand the average dollar amount per project increased from $\$ 227,000$ in 1995 to $\$ 368,000$ in 1999 (in nominal terms). Notice though that the average size of projects for large firms declined quite steeply, whereas that of small and medium firms increased a great deal. Large firms commanded about $40 \%$ of grants (in dollar terms) for most of the period, but their share of the budget declined steeply in 1999, to $23 \% .{ }^{25,26}$

\section{The OCS and the Rise of the High-Tech Sector}

So far we have described the structure and programs of the OCS, and presented quantitative indicators of its activities over time. The natural questions that one would like to pose now are those related to the impact of the OCS: To what extent has the OCS fulfilled the goals envision by the 1985 law? What effect have the various OCS programs had on the high-tech sector and on the economy at large? And so forth. First we review existing econometric studies, then we discuss some economic indicators contrasting R\&D-intensive sectors with traditional ones, and lastly we present an overview of the rise of the high-tech sector in Israel with the help of patent data.

Review of Econometric Studies The consensus in Israel is that the OCS indeed played a key role in the emergence and development of the high-tech sector, a role that went beyond the mere administration of grants. There have been various studies in Israel examining inter alia the impact of $R \& D$ expenditures on productivity at the firm level (Bregman, Fuss, and Regev 1991; Griliches and Regev 1995; Bregman and Merom 1998). They all find that the returns to R\&D have been high, and in particular significantly higher than investments in physical capital. However, these studies do not address the effect of government support per se.

If one could assume that OCS grants brought about higher total R\&D outlays (this is commonly referred to as additionality), then the findings of high returns to R\&D would imply also positive returns to government support. Capital markets were extremely limited in Israel during the early stages of development of the high-tech sector there (i.e. in the 1970s and 1980s), and hence it is very unlikely that R\&D grants supplied by the OCS would have crowded out private R\&D funds back then. Later on, though, internal reform as well as international 
openness greatly increased the availability of funds to industry, bringing back to the forefront the additionality issue, certainly for the 1990s.

The basic conundrum posed by additionality is the obvious lack of counterfactuals (i.e. "what would the recipient firm have done had it not received an R\&D subsidy?"), which effectively means the lack of appropriate controls (i.e. data on nonrecipients that are otherwise similar to the recipients). Several recent papers have tried a variety of approaches to deal with it (see for example Busom 2000 and Wallsten 2000 ), but the jury is still out both on method and on stylized facts. ${ }^{27}$ Feldman and Kelley (2000) come closest to having an appropriate control group: they followed both winners of Advanced Technology Program (ATP) grants and applicants that failed to receive grants. Surveying both types of firms, they find prima facie evidence of additionality: nonawardees tend not to pursue the proposed projects by themselves, awardees are more successful in seeking additional funding for the projects, etc.

Lach (2000) carefully examines this issue for a sample of Israeli manufacturing firms that performed R\&D during the period 1991-95, and finds that the R\&D subsidies granted by the OCS in fact stimulated long-run company-financed R\&D expenditures. According to his estimates, an extra dollar of R\&D subsidies increases long-run company-financed R\&D by 41 cents (evaluating the effect at the mean of the data). Thus, total R\&D outlays increase at the margin by 1.41 dollars: the full amount of the subsidy, plus the additional, induced effect of 41 cents. However, it is not clear to what extent those results are robust, either to the choice of specification or to that of instruments; in fact, in other specifications Lach finds little or no additionality. The problem resides mostly in the paucity of the data (there are not many firms with any given set of characteristics at any point in time that can serve as controls for those receiving subsidies) and in the difficulty in finding appropriate instruments.

Taking a different track, Griliches and Regev (1999) examine whether the source of R\&D funds per se (private vs. OCS grants) makes a difference in productivity (once again in a panel of firms), regardless of additionality. They find that it does: government-funded R\&D appears to be significantly more productive than privately financed $R \& D$, by a surprisingly large margin. The reason may be rooted in the ability of the OCS to pick winners, and/or in the fact that the very process of applying for grants may compel firms to self-select projects, use more 
structured preassessment and planning techniques, etc. Finally, an unpublished study commissioned by the OCS itself examined the contribution of OCS grants to sales, exports, and the like, relying on detailed data from the OCS and on an extensive survey of firms (Michlol, 1999). The study finds very high "multipliers" per dollar of OCS support, higher for small firms than for large ones; however, the study is careful to point out its limitations, particularly given the lack of a suitable control group.

The evidence thus far available from these studies, then, provides econometric support, albeit limited, to the presumption that OCS grants have had a positive and significant effect on productivity in R\&D-intensive sectors, and through them on the economy as a whole. Still, there is a long way to go in that respect, if only because a major ingredient of the rationale for government support to $R \& D$, namely spillovers, has not been investigated at all. Beyond the aforementioned studies, we present now some evidence on the development of the high-tech sector itself, with the implicit understanding that the OCS was one of the main drivers behind the rise of this sector. We do that in two ways: first, we briefly recount reports from the Bank of Israel on the performance of technologically advanced sectors vis-à-vis traditional ones; second, we present an overall view of innovation in Israel, relying on comprehensive and highly detailed information on Israeli patenting in the U.S.

Aggregate Sectorial Indicators ${ }^{28}$ Responding to the rapid changes in the composition of industry, and in particular the raise of the high-tech sector, the Research Department of the Bank of Israel introduced in the mid-1990s a new classification of the manufacturing sector: it was divided into "advanced," "traditional," and "mixed" sectors, according to the quality and composition of the labor force (e.g. the percentage of scientists and engineers), the quality of the capital stock, and the relative size of the R\&D stock. ${ }^{29}$ Table 3.5 presents selected indicators according to this classification.

The advanced sectors outperformed the two other categories in virtually all dimensions during the reported period (1995-98). The differences between them increased substantially in 1997 and 1998, a period of rather severe recession. During those years the advanced sectors grew at a rate of $6 \%$ per year, whereas the others remained stagnant or declined. Similarly, exports from advanced sectors grew at a stunning $18.5 \%$ per year, whereas the mixed sectors exhibited an anemic 3\% growth, and the traditional sectors declined $1.4 \%$. Thus, it is clear that 
Table 3.5

Performance indicators by type of sector, 1995-98

\begin{tabular}{lcccc}
\hline & & \multicolumn{3}{c}{ Annualized rate of change, (\%) } \\
\cline { 3 - 5 } Indicator & Period & $\begin{array}{c}\text { Advanced } \\
\text { sector }\end{array}$ & $\begin{array}{l}\text { Mixed } \\
\text { sector }\end{array}$ & $\begin{array}{c}\text { Traditional } \\
\text { sector }\end{array}$ \\
\hline Production & $1995-96$ & 8.0 & 6.3 & 5.9 \\
Labor productivity & $1997-98$ & 6.0 & 0.3 & -1.8 \\
& $1995-96$ & 3.5 & 2.4 & 4.2 \\
Capital stock & $1997-98$ & 4.5 & 0.6 & 2.2 \\
& $1995-96$ & 10.7 & 6.4 & 9.7 \\
Exports & $1997-98$ & 10.0 & 6.1 & 6.8 \\
& $1995-96$ & 9.0 & 10.5 & 2.7 \\
\hline
\end{tabular}

Source: Bank of Israel, Annual Report for 1998, table B 10 (p. 56).

Israeli manufacturing is shifting away from traditional industries and into technologically advanced, export-oriented sectors.

A further indicator is the rapid growth of high-tech exports in the course of the last decade, both in value terms and as a share of total exports, as shown in table 3.6. High-tech exports include communications, monitoring, medical and scientific equipment, electronic components, office machines, and computers.

Innovation in Israel: Patent Indicators ${ }^{30}$ Patent-based statistics are often used as indicators of innovative activity. Indeed, their very wide coverage, long time series, and richness of detail make them a unique and compelling data source for the study of technical change. There are also limitations: not all innovations are patented, both because of failure to meet patenting requirements and because of strategic considerations. We present in this section an overview of innovation in Israel based on all patents awarded to Israeli inventors in the U.S. during the period 1968-97 (over 7000 patents), as well as patents of inventors in comparison countries. Given that the high-tech sector in Israel is overwhelmingly export-oriented, and that the U.S. is a prime destination for those exports, there is reason to believe that Israeli patents issued in the U.S. are representative of the main technological trends and patterns in Israel.

Figure 3.1 shows the number of successful Israeli patent applications in the U.S. over time, starting in 1968. The growth in the annual number of patents has been very impressive, starting from about 50 in the 
Table 3.6

Israeli high-tech exports

\begin{tabular}{ccc}
\hline Year & High-tech exports (\$ millions) & \% of total exports \\
\hline 1988 & 1282 & 14 \\
1989 & 1417 & 13 \\
1990 & 1660 & 14 \\
1991 & 1734 & 15 \\
1992 & 2188 & 18 \\
1993 & 2889 & 21 \\
1994 & 3350 & 21 \\
1995 & 3569 & 20 \\
1996 & 4066 & 21 \\
1997 & 4885 & 23 \\
1998 & 5483 & 27 \\
1999 & 6077 & 27 \\
2000 & 9605 & 34 \\
\hline
\end{tabular}

Source: Israeli Central Bureau of Statistics.

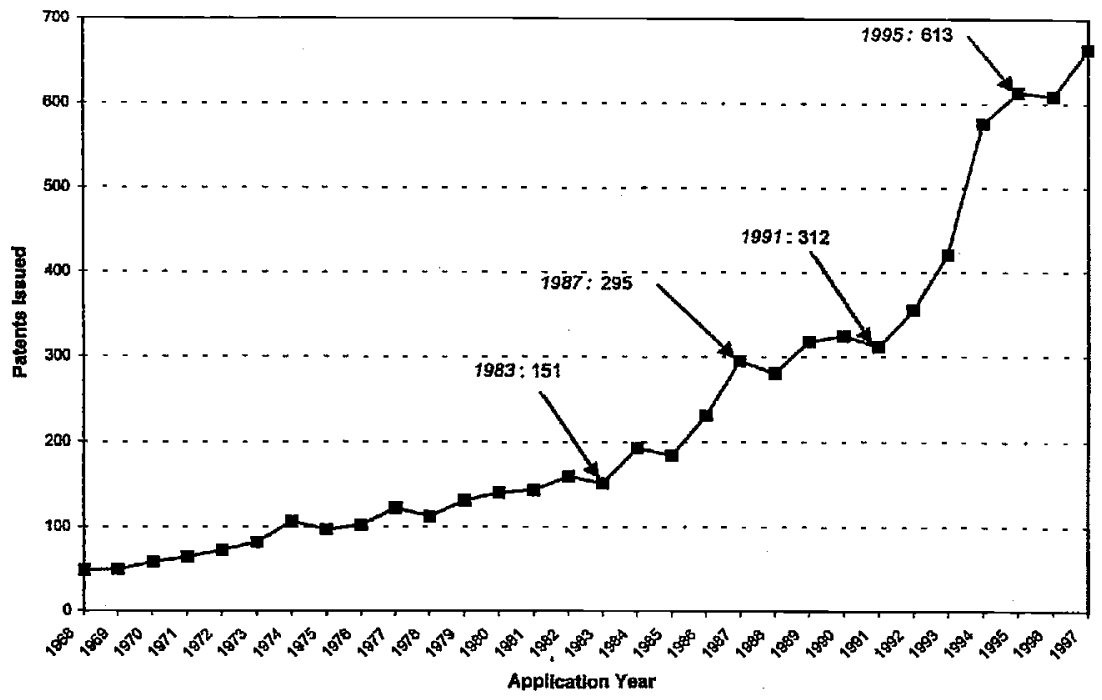

Figure 3.1

Israeli patents in the U.S.- 1968-97, by application year. 
late 1960s, to over 600 in the late 1990s. However, the process was not smooth, but was characterized by big swings in growth rates. Particularly striking are the two big jumps that occurred in the second half of the period: from 1983 to 1987 the number of patents doubled, and it doubled again from 1991 to $1995 .{ }^{11}$ Figure 3.2 shows industrial R\&D expenditures (in constant 1990 dollars) along with patents. ${ }^{32}$ There is clearly a (lagged) comovement of the two series, as manifested for example in the following simple Pearson correlations ${ }^{33}$ :

\begin{tabular}{lcccc} 
& $R \& D$ & $R \& D(-1)$ & $R \& D(-2)$ & $R \& D(-3)$ \\
\hline Patents & 0.850 & 0.877 & 0.884 & 0.883 \\
$\log$ (patents) with $\log (\mathrm{R} \& D)$ & 0.890 & 0.901 & 0.922 & 0.928 \\
\hline
\end{tabular}

Thus, patents lead R\&D by $2-3$ years, and the correlation is stronger in rates (i.e. when using logs) than in levels. Looking in more detail, there is a striking run-up in R\&D from 1981 to 1986 (in particular, R\&D expenditures more than doubled between 1980-81 and 1984-85), followed by the doubling of patents between 1983 and 1987. This is the period that saw the emergence of the high-tech sector, and that is well reflected in both series. In 1986-88 we see a decline in the level of R\&D spending, and the concomitant flattening of patenting in 1987-91, and

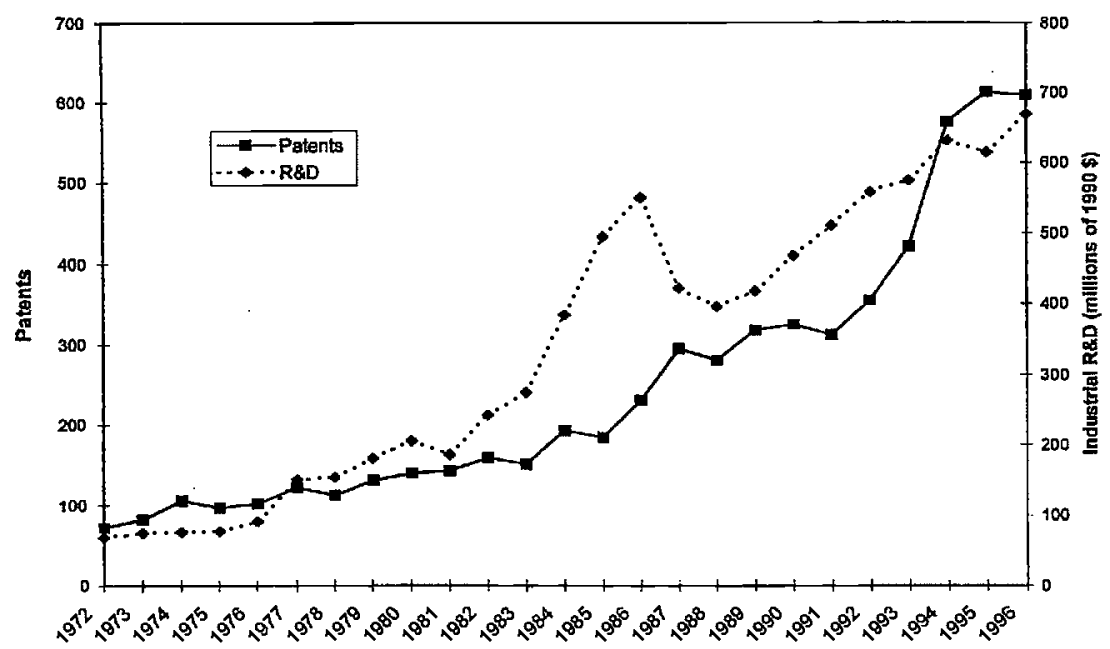

Figure 3.2

Israeli patents and industrial R\&D. 
then again a sustained increase through the early-mid nineties that anticipates the second big jump in patenting.

Although we do not have official figures for R\&D grants from the OCS prior to 1988, available figures indicate that the behavior of the time series for grants is very close to that of total $R \& D$ industrial spending (see for example Griliches and Regev 1999, table 6). In particular, from 1981 through 1986 OCS grants also doubled, they flattened during 1986-88, and they grew fast again up to the mid-1990s (see table 3.1 for the latter). It is clear then that industrial $R \& D$ expenditures are closely linked (with a reasonable lag) to patents, and so are R\&D grants awarded by the OCS. Further research is needed to unravel the joint dynamics.

International Comparisons We resort to international comparisons in order to put in perspective the overall level and trend over time in Israeli patenting. We do that with respect to three different groups of countries: (1) The G7: Canada, France, Germany, Italy, Japan, the U.K., and the U.S.; (2) a reference group: Finland, Ireland, New Zealand, and Spain $^{34}$; and (3) the Asian tigers: Hong Kong, Singapore, South Korea, and Taiwan.

Figures 3.3-3.5 show the time patterns of patents per capita for Israel vs. each of the above groups of countries. We normalize the number of patents by population, simply because this is a widely available and accurate statistic that provides a consistent scale factor. ${ }^{35}$ Figure 3.3 reveals that Israel started virtually at the bottom of the G7 (together with Italy), but by 1987 it had climbed ahead of Italy, the U.K., and France and was on a par with Canada. In the early-mid nineties it moved ahead of Canada and (the unified) Germany, thus becoming third after the U.S. and Japan. Using civilian R\&D as deflator for these countries shows a similar result. Thus, there is no question that Israel had surged forward and placed itself in the forefront of technologically advanced countries, at least in terms of (normalized) numbers of patents.

The comparison with the reference group reveals that the only country that is "game" is Finland, which has followed a pattern virtually identical to Israel. The other three countries are well behind, and have remained at the bottom without any significant changes over time. As to the Asian tigers, we can see immediately that Taiwan has grown extremely rapidly since the early eighties, actually surpassing Israel in 1997. And indeed, Taiwan is widely regarded today as a high-tech powerhouse, after being associated with low-tech, imitative behavior for a long time. South Korea seems to be embarked on a similar path. By contrast, Hong Kong and Singapore remain well behind. 


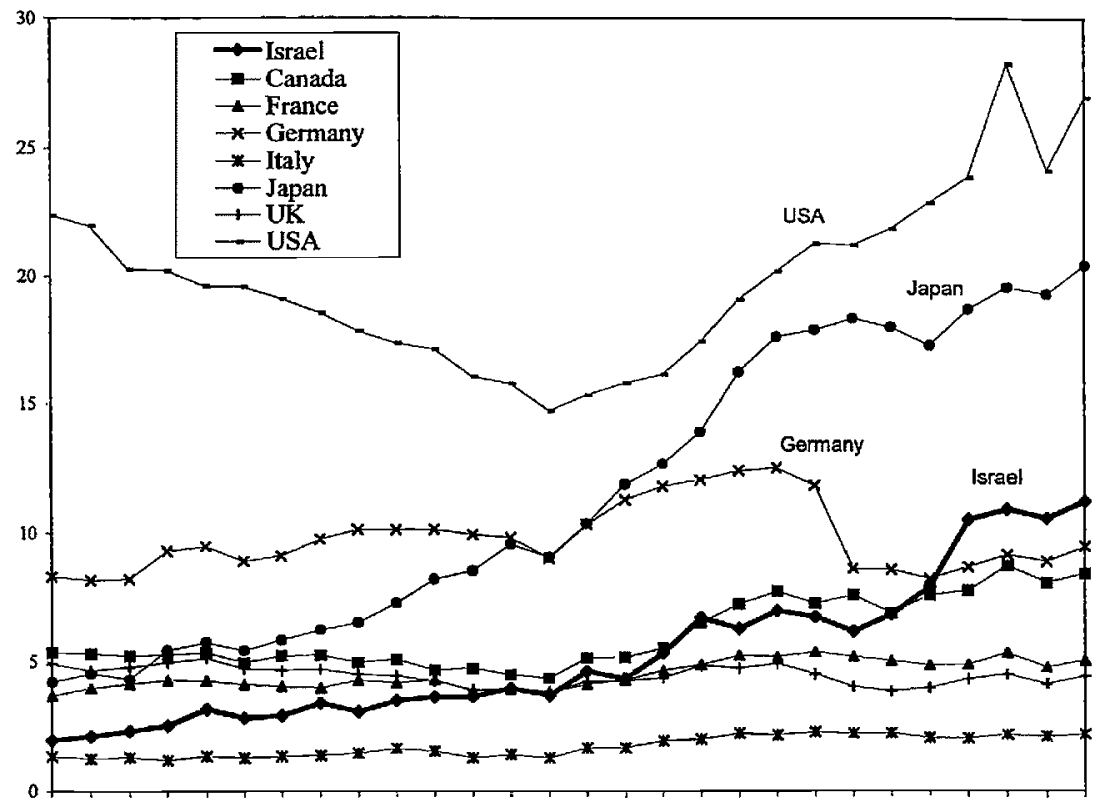

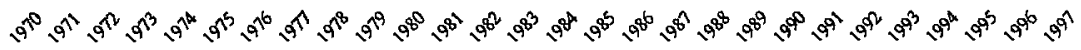

Figure 3.3

Patents per capita: Israel vs. the G7 (patents per 10,000 population).

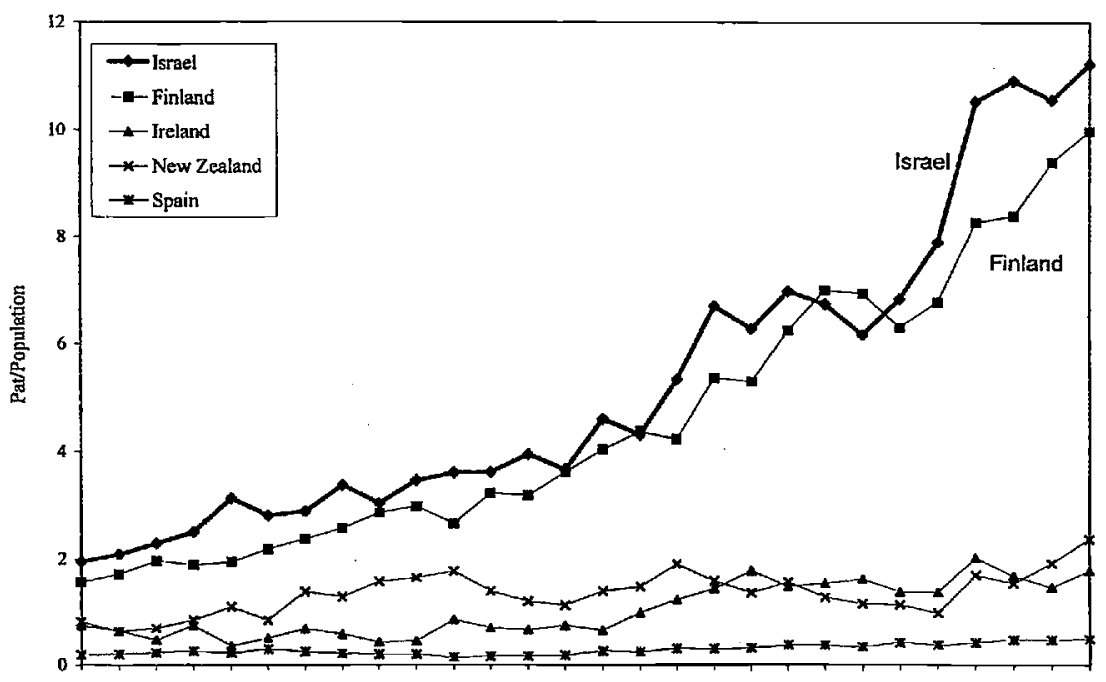

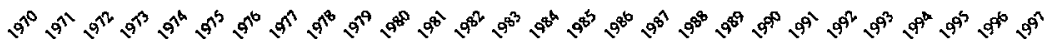

Figure 3.4

Patents per capita: Israel vs. the reference group (patents per 100,000 population). 


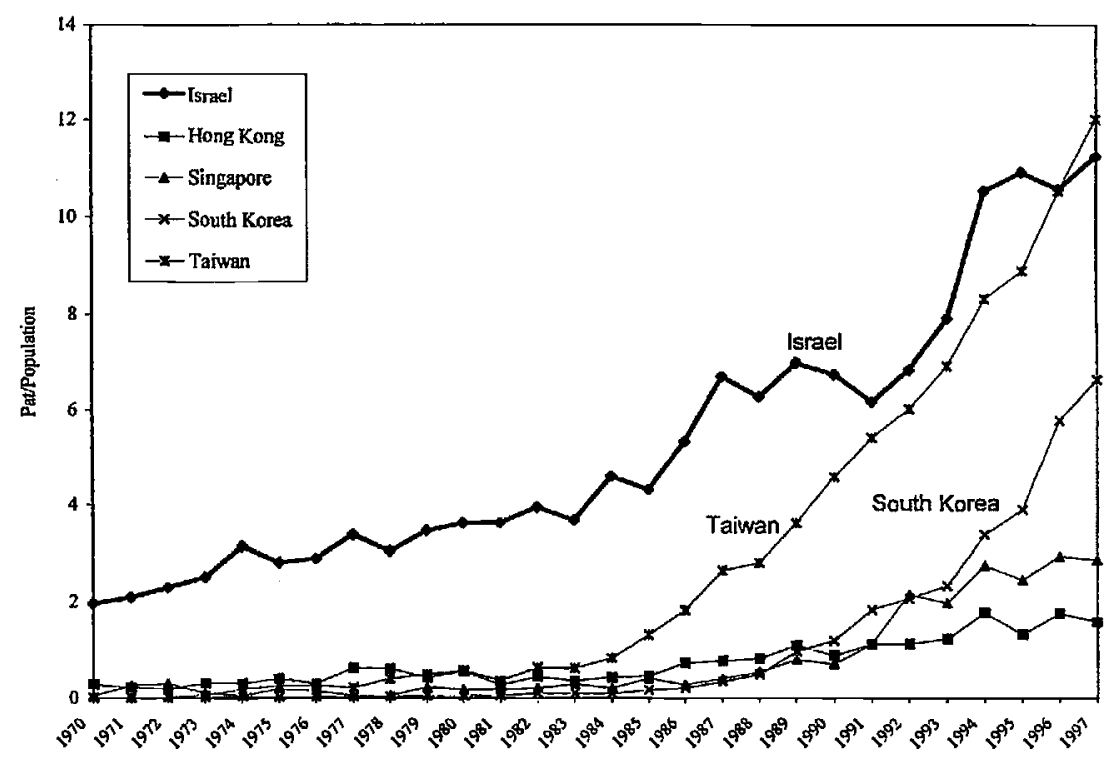

Figure 3.5

Patents per capita: Israel vs. the Asian tigers.

Comparisons based on normalized patent counts notwithstanding, many aspects of the innovation process require a critical mass, and for those purposes it is the absolute size of the innovative sector that counts, as proxied here by the (absolute) number of patents. Israel has still a long way to go in those terms: it stands well below all of the G7 countries, and is about one-fourth the size of Taiwan and South Korea. The question is whether there are forces in the Israeli economy capable of keeping the momentum going for the high-tech sector, bringing it up to the size required and ensuring its long-term viability. The stagnant budgets awarded in recent years to the OCS are not a good omen in that respect.

The Technological Composition of Israeli Patented Innovations The U.S. Patent Office has developed over the years an elaborate classification system by which it assigns patents to some 400 main patent classes, and over 150,000 patent subclasses. We have developed recently a new classification scheme, aggregating these 400 patent classes into six main categories: the three traditional categories chemical, mechanical, and others; the two upcoming categories computers and communications and drugs and medicine; and the in-between category electrical and electronics. Up until the early 1980s the shares of these categories were 
quite stable in the U.S.: the traditional categories were the highest, whereas drugs and medicine and computers and communications accounted just for a tiny fraction, up to $5 \%$ each. Starting in the early 1980s the top three fields decline, whereas the bottom two surge forward, with computers and communications accounting by 1994 for over $15 \%$ of all patents.

The pattern for Israel is similar, except that the changes are more abrupt. The most striking development is the surge of computers and communications from about $5 \%$ in the 1970s (as in the U.S.), to a full $25 \%$ by 1994 and beyond. Likewise, drugs and medicine doubles its share from $10 \%$ to $20 \%$. The flip side is the much more pronounced decline in the traditional categories, with chemical exhibiting by far the sharpest drop, from $40 \%$ at the beginning of the period to less than $10 \%$ by 1996. The composition of innovations has thus changed dramatically in Israel, and seemingly in a healthy way, in that they are in tandem with worldwide changes in technology, except that Israel is experiencing them at an accelerated rate.

Who Owns and Who Benefits from Israeli Patented Innovations? The patent-based indicators mentioned so far suggest that Israel's innovative performance has been quite impressive. However, the question arises whether the Israeli economy can take full advantage of the innovations generated by Israeli inventors, in view of the composition of the patent assignees, i.e. of the owners of the intellectual property rights to those innovations. In fact, just about half of all Israeli patents granted in the last 30 years are owned by Israeli assignees (corporations, universities, or government): the rest belongs to private inventors (unassigned patents) or to foreign assignees. This percentage is lower than in most of the comparison countries, certainly much lower than the corresponding figure for the G7 countries except Canada (local assignees made $74 \%$ of patents in the U.S., $96 \%$ in Japan). The presumption is that (local) economic gains from innovation are correlated with this figure, and furthermore, that they are correlated with the percentage of patents owned by local corporations (just $35 \%$ in Israel). The trend is encouraging, though: the percentage of patents that belong to Israeli corporations has been rising steadily, and stands now at close to $50 \%$.

The overall picture that emerges from these patent indicators is thus mixed: on the one hand Israel exhibits a rapidly growing and vibrant innovative sector, which has achieved an impressive international standing. On the other hand, the Israeli economy has still a way to go 
in order to achieve critical mass and to realize the economic benefits embedded in those innovations.

\section{R\&D Policy in Israel-A Reassessment ${ }^{36}$}

Having described the programs and basic ingredients of R\&D policy in Israel towards the industrial sector, we now undertake to examine the contents of that policy. Unfortunately, the lack of rigorous empirical research in this area hampers the formulation of sound, long-term, and well-grounded policies. Nevertheless, we shall scrutinize the policies currently in place and their implementation mechanisms, and evaluate proposals for changes in them that are called forth by recent developments. This should be seen just as an opening salvo, aimed primarily at fostering public debate in this area (see also Teubal (1999), who lays out a detailed proposal for an R\&D strategy for Israel).

First, we look at the system by which grants are allocated: with the recent imposition of a rigid budget constraint on the OCS, the present system is basically untenable, and hence we examine various alternatives that will incorporate this new reality. Second, we examine a series of policy issues that go beyond the allocation of funds: the payback system, the conditionality on production in Israel, etc. Third, we look in detail into the Magnet program, and the rationale for supporting it vs. the regular OCS grants. Fourth, we review the difficulties in setting a policy target for R\&D spending, and lastly we ask whether government policy should be aimed also at the supply side or the market for R\&D personnel, rather than just keep subsidizing the demand side.

\section{Rethinking the Rules of the Game in View of a Rigid Budget Constraint}

Background The R\&D Law in Israel does not address the thorny issue of how to allocate a (rigid) budget for R\&D support if the demand for such support exceeds the budget provision. That is, the OCS support program was not meant to be competitive, and in principle it should provide $\mathrm{R} \& \mathrm{D}$ subsidies to all projects that pass the eligibility criteria. The latter are based on technological and commercial feasibility, and other procedural considerations. Projects are judged one by one, and there is no attempt to rank them or otherwise establish a funding priority. The paramount principle of neutrality, which has been a cornerstone of R\&D policy in Israel since the late 1960s, also precludes picking projects according to field or any other such consideration. 
In 1997 the projected demand for R\&D support greatly exceeded the budget provision (by about $50 \%$, i.e. some $\$ 200$ million), and the Treasury refused to consider any substantial increase in the OCS budget to accommodate such demand. ${ }^{37}$ An impasse ensued, bringing a great deal of uncertainty to the working of the OCS and to the high-tech sector as a whole. A committee was formed to try to find a way out of the crisis. After months of deliberations the committee could not reconcile the conflicting forces at play: on the one hand the imperatives of the existing law, the expectations of the high-tech sector based on it, and the perceived need to expand the R\&D support budget in order to accommodate and foster the success of the high-tech sector; and on the other hand the sudden imposition of a rigid budget constraint that did not allow for any growth of demand.

The result has been ad hoc tinkering both with the OCS budget and its way of operation, in order to keep the system running without solving the underlying issues. More importantly, this protracted crisis made it clear that the R\&D law as is, and the implementation mechanisms in place, are in need of extensive revision in view of the explosive growth of the high-tech sector (as well as the rapid changes that took place within the sector), and the pressure that puts on the R\&D support budget in an era of fiscal restraint. ${ }^{38}$ Following is a discussion of the set of policy issues that lie at the core of this conundrum. The basic premise underlying the discussion is that, if current procedures are left unchanged, demand for R\&D support will exceed present level budgets by wide margins, ${ }^{39}$ and hence there is an urgent need to design a suitable allocation mechanism.

There are essentially two ways to go about allocating a fixed budget to projects that request support in excess of available resources. The first is to depart from the principle of neutrality in some dimension, the second to design an allocation mechanism that will do the job. Of course, the two are not mutually exclusive, and one could have a combination of both. We consider each in turn, starting with the latter.

Allocation Schemes for the Regular OCS Program of RED Grants Until now the system has been such that all eligible projects are supposed to be supported, and in principle the support should be equal across projects (in percentage terms). The eligibility criteria entail checks of technological and commercial feasibility (or "viability"), the good standing of the applicants, and other administrative criteria. There are three main options for moving away from this system: (1) to adjust continually the support rates or the eligibility criteria so as to meet the budget 
constraint; (2) to implement a competitive ranking system; (3) randomization.

The first option entails adjusting the support rates or the eligibility criteria with every new budget so as to meet the budget constraint. The major drawback is of course the uncertainty that such a policy shift will introduce, greatly impairing the ability of firms to plan ahead (certainly in the long term). In addition, this would make the whole support system vulnerable to political manipulation.

The second option simply means that projects would have to compete against each other for scarce support funds (as happens with the Magnet program). There will be a ranking system, and the funds will be allocated from the top down until the budget is exhausted. A serious issue that will almost certainly arise in such a context is whether or not the system is compatible with neutrality, in view of the fact that any ranking system will be extremely hard to implement across fields, so that the ranking would have to be done primarily within fields. ${ }^{40} \mathrm{How}$ ever, it may be that in any case the system will have to move away from neutrality (see below).

The last option is some sort of randomization, that is, to chose at random from the set of projects that pass some eligibility threshold (as in the present system), up to the point where the budget constraint is met. We shall not analyze this option in any detail, simply because it would seem that it is (at least at present) politically infeasible. ${ }^{41}$ Thus, it seems that the only viable alternative at this point is to implement some sort of competitive ranking system, as suggested above, and combine it with a conscious departure from neutrality.

Departures from Neutrality As already mentioned, one of the hallmarks and basic premises of the OCS support programs all along has been neutrality, that is, the OCS does not select projects according to preferred fields or any such criteria, but responds to demand that arises spontaneously from industry. It is fair to say that this policy has been eminently successful, since it basically reinforced existing competencies and emerging comparative advantage. Moreover, it avoided one of the main dangers of any industrial policy, namely, the picking of winners by government officials.

However, the fiscal constraint on the overall support budget implies that the OCS may have to depart from neutrality in any case, in which case it is certainly better to do it explicitly as a result of serious analysis, and not by default. There are at least two dimensions along which the 
OCS could opt for nonneutral allocation policies: according to fields, and according to type (or rather size) of firms. ${ }^{42}$ As already suggested, such departures could be made part of a revamped allocation scheme (e.g. by adopting a competitive ranking system).

Departing from neutrality with respect to technological fields is always dangerous, since it implies guessing future technological and/or market developments, and deciding by committee what is better left to the market. Thus, one should avoid it except if there are some glaring market failures that need to be remedied. There is room to believe that may be the case at present in Israel with the field of biotechnology. Israel has a very talented and plentiful workforce in life sciences. Yet, this pool of human capital in one of the most dynamic technological areas at present, and potentially one of the most important future growth areas, has yet to make a mark on industry (i.e. in biotech). Thus, there is room to consider taking a more active and entrepreneurial attitude towards this sector (not necessarily by channeling more funds to it), but that requires further study.

The second possible departure from neutrality is differential support to firms of different sizes. We discuss this option now in more detail.

Departing from Neutrality: Large vs. Small Firms In principle, the support policies of the OCS do not make any distinction among types of firms with respect to eligibility for the existing flat rate of support $(50 \%$ of the approved R\&D budget). ${ }^{43}$ In practice, though, and as described in Section $I I$, the support for large firms during the past two years has been reduced, reversing the previous trend whereby a handful of very large firms (large by Israeli standards) accounted for a large proportion of the total support dispensed. However, this de facto change has been essentially an ad hoc response to budgetary pressures (and hence is likely to be temporary), and not a well-formulated policy reassessment. Thus, we still have to examine whether the principle of equal support to all firms regardless of size is a reasonable policy. In other words, the question is whether the rationale for R\&D support (in terms of market failures etc.) holds equally for small and large firms. A brief review of the basic economic rationale for support of $R \& D$ reveals that indeed there is room to (re)consider the prevailing policy, and reduce the rate of support to large firms vs. smaller ones.

First, the larger is the firm, the more able it is to internalize the spillovers that it generates, and hence the smaller will be the divergence between the social and the private rate of return on the R\&D that 
it performs. One of the main goals of government support to private $R \& D$ is precisely to bridge the gap between the two rates of return: absent that support, firms will do too little R\&D (relative to the socially desirable level), and hence the support is meant to encourage them to increase that amount past what is profitable according to the private rate of return on it. However, the more a firm manages to capture the spillovers that stem from its R\&D projects, the less room there is to subsidize it on that basis. Size matters in that respect: small firms are hardly able to capture the externalities that they generate, but that ability increases as they grow larger.

A further rationale for government support of $R \& D$ has to do with risk and risktaking. First, the degree of risk of an $R \& D$ project from an economy-wide point of view may be lower than that perceived by private firms; or, closely related, the risk premium demanded by private investors may be higher than warranted, because of asymmetric information. Second, the degree of risk aversion by private investors may be higher than the social rate. As a result, the market may provide for too little risktaking in $R \& D$, and hence government support would encourage firms to move in the socially desirable direction.

The point in the present context is that there might be substantial differences in this respect between small and large firms. First, problems of asymmetric information are usually more acute for younger/smaller firms, and hence the risk premium that smaller firms are required to pay is often much higher. Second, R\&D projects undertaken by small firms are, ceteris paribus, riskier than if done by larger firms, even if they are exactly the same in terms of technological goals. This is so because younger/smaller firms are disadvantaged relative to large firms in terms of a wide range of competencies and experience that are complementary to R\&D: in marketing, pure management, access to complementary know-how, etc. Thus, there is more room to subsidize risktaking by small firms than by larger ones.

Lastly, imperfections in capital markets usually affect small firms more than large firms. First, the availability of internal financing, which has been shown to be important in the context of $R \& D$, is normally less constraining for older/larger firms than for smaller ones. Second, access to global capital markets is easier/cheaper for larger firms. Thus, government support to R\&D meant to bridge those imperfections ought to be channeled more towards small firms than to larger ones.

These considerations suggest that there is room to consider supporting small firms at higher rates than larger firms. One could envision the 
following support structure: Going startups (up to $5 \mathrm{M} \$$ sales) (4) $^{44} 66 \%$; small to medium-size firms (5-100 M\$ sales): $50 \%$ (as at present); large firms (over $100 \mathrm{M} \$$ sales): $33 \%$. This is of course just an example-a serious proposal would have to pay a great deal of attention to the cutoff levels, the implications for the budget, etc.

\section{Further Policy Issues}

The Payback Scheme (Recoupment) At present the policy is that successful projects (i.e. projects that eventually lead to sales) are required to pay back to the OCS the amount of support received, but the payback cannot account for more than a small percentage of annual sales. ${ }^{45}$ The idea is that this way the OCS shares the risk of the R\&D projects (effectively lowering the risk premium that private firms have to pay), and overcomes possible imperfections in capital markets by offering easily accessible finance. Moreover, it subsidizes R\&D both in that it demands zero interest on the conditional loan, and (as already mentioned) in lowering the risk premium. There are, however, serious drawbacks to such a system:

- Since the payback obligation applies to sales that stem directly from the projects supported, this immediately creates moral hazard problems with regard to how projects are defined, and all sorts of pernicious incentives for choosing how to relate products and sales to projects.

- The previous issue implies that the OCS and the firms supported find themselves engaged in an antagonistic, confrontational situation that is detrimental to the efficient functioning of both.

- As we have seen in Section II, the importance of payback funds in the overall OCS budget is growing steeply over time, and there is a danger of political opportunism in this respect, namely, that the commitment to R\&D support may diminish, but in the short run that could be disguised by increased reliance on payback funds in order to support new projects.

Beyond those issues, the payback scheme may have had the unintended consequence of blurring the real intent of the R\&D Law, obscuring the true extent of the support budget, and hence the commitment of the government to $R \& D$. As we have seen, such support is warranted for good economic reasons, which indeed call for a subsidy to R\&D. 
Contrary to some widely held perceptions, the intent and rationale of the R\&D Law is not for the government to assume just a financing role, in view of imperfections in existing financial markets in Israel. The main intent is to bridge the gap between the social and the private rate of return to $R \& D$, and that calls for a straight subsidy. The recent availability of venture capital and the opening of the Israeli economy to foreign capital markets may reduce the effective cost of capital and perhaps also the risk premiums to Israeli high-tech firms. However, that has nothing to do with the fact that these same firms generate spillovers to the Israeli economy that they can only partially appropriate, a fact that calls for subsidizing R\&D.

Thus, there is room to consider the phasing out of the payback scheme, or at least the offering of an alternative track consisting of a lower subsidy rate but without a payback proviso. If the payback scheme is eliminated, the R\&D grants given by the OCS will become strictly and overtly what they were designed to be, namely, a straight subsidy, hence doing away with the hazards of political opportunism.

The Conditionality of Production in Israel The R\&D Law stipulates that if the OCS extends support to an R\&D project, the innovation resulting from it should be produced in Israel. In fact, the law states as one of its goals to increase employment in that way. It should be clear that such conditionality might lead to serious allocational inefficiencies. Denote by $c_{I}$ the costs of producing in Israel, by $c_{A}$ the costs of producing abroad, and by $S$ the R\&D subsidy. It is trivial to show that, if $c_{I}-$ $c_{A}<S$, the firm will choose to take the R\&D subsidy, execute the project in Israel, and produce there even though production in Israel is more costly than abroad. If the inequality is reversed, then the project will be carried out abroad entirely (including the R\&D). Denote the cost disadvantage by $S^{\prime}=c_{I}-c_{A}$. In the case where $c_{I}-c_{A}<S$, we can see that the R\&D subsidy is in fact composed of two parts: $S=S^{\prime}+\left(S=S^{\prime}\right)$. The first part, $S^{\prime}$, is then a subsidy to production, not to R\&D, and only the second part is a true R\&D subsidy. The larger is the gap between production costs in Israel and those abroad, the more the R\&D grants are in fact subsidizing inefficient production that quite likely would not be otherwise located in Israel.

Thus, there is room to consider the elimination of this provision of the law: there is no strict economic rationale for it, and it leads to production inefficiencies. Israel presumably has a comparative advantage in $R \& D$, not in the assembly of "boxes" containing the sophisticated innovations produced there. It should be clear also that if this condition- 
ality is repealed, then the effective R\&D subsidy could be increased without increasing the actual amount of funds disbursed. Denote by $S_{N}$ the new subsidy; then one could have $S-S^{\prime}<S_{N}<S$. Of course, the government can legitimately try to encourage local employment, and see the R\&D Law as one of the means to do so. In that case, though, it should be clear that part of the grants constitute in fact an employment subsidy, and should not be counted as R\&D support.

Policy Changes and Support for Large Firms We suggested above that the rate of support for large firms could be set at a lower level than that for smaller firms. However, we envision the implementation of these policy changes as a comprehensive package. In that case, while lowering the nominal rate of support to large firms, the effective rate may actually increase, both because of the phasing out of recoupment and because of the conditionality to produce in Israel. This latter provision is likely to affect larger firms more than smaller ones, since for larger firms the options and opportunities to produce abroad are much more extensive. As to the payback scheme, it is also likely that the percentage of successful R\&D is higher for larger firms, and hence that the payback burden is also disproportionally higher for them. On both accounts, then, larger firms stand to gain from the repeal of these provisions, thus compensating for the lower support rate.

Ongoing Economic Assessment and Policymaking The drawing of sound economic policies towards R\&D, innovation, and the high-tech sector is of paramount importance for the Israeli economy. At present, though, there is no body in charge of setting such policies, and hence things happen in a rather haphazard way, in response to successive pressures and developments. What is needed is an economic policy unit, probably at the OCS, with the following mandate: (1) to collect and organize in a comprehensive and coherent way the data needed for policymaking; (2) to set procedures for the ongoing evaluation of the effectiveness of the OCS policies; (3) to evaluate, research, and discuss long-term policies. It is interesting to note that the Advanced Technology Program in the U.S., which is the closest to the OCS in terms of intent, has such a unit as an integral part of its mission and mandate.

\section{The Magnet Program vs. the Regular OCS Fund}

As already mentioned, the Magnet program supports consortia of industrial firms and academia, aimed at developing "generic, 
precompetitive technologies" common to the members of the consortia. Magnet finances two-thirds of the R\&D budget of the consortia with straight grants, and there is no payback obligation. Contrary to the regular program of the OCS, Magnet selects consortia on a competitive basis, and allocates in this manner a budget of about $60 \mathrm{M} \$ / \mathrm{yr}$ to the winning consortia.

One of the phenomena that underlies the need for the Magnet program is the fact that R\&D efforts in the Israeli high-tech sector have been rather fragmented. That is, this sector is characterized by the existence of a very large number of small to medium firms, a handful of large ones (but none with sales of over $\$ 1$ billion), and a great deal of turnover. ${ }^{46}$ There is no question that the vitality, the daring, and some spectacular successes of the sector owes in no small measure to these features, which provide favorable conditions for an accelerated Darwinian process. On the other hand, these same features call into question the ability of the sector, and of the Israeli economy as a whole, to reap long-term economic benefits from its own success. The recent sales of a series of highly successful Israeli companies to foreign corporations are just one of the manifestations of this syndrome.

Fragmentation was perhaps unavoidable, certainly in the initial stages of development of the high-tech sector, since the overwhelming majority of high-tech firms grow out of startups established by single technological entrepreneurs. Moreover, most of them aim (at least initially) at narrowly defined market niches. As the sector moves on, though, size matters: in order to tackle larger markets and contemplate accordingly longer-term projects, there is need for larger entities, and that in turn calls for various forms of cooperation, joint ventures, mergers, and acquisitions. However, for reasons that we do not profess to understand, too little seems to be happening in that respect internally (i.e. within Israel). In fact, we witness time and again not only failures of cooperation, but even serious informational failures, in the sense that potential partners are unaware of the existence of each other, and/or of the potential for mutually beneficial cooperation. ${ }^{47}$

Given this background, the importance of Magnet may lie not so much in its formally stated mission (i.e. supporting generic $R \& D$ ) as in the fact that it fosters cooperation, it facilitates the creation of larger (sometimes virtual) entities, it disseminates information about possibilities for joint ventures, and it encourages individual firms to seek such information. Contrary to deeply rooted belief, one cannot just assume that if there are profitable opportunities for cooperation they will necessarily be realized - the institutional framework matters. 
It is therefore quite certain that the economic rationale for government support to $R \& D$ is strongest for a program such as Magnet, both for the aforementioned reasons and for more traditional (but equally important) ones, namely, that it deals with generic projects and strongly emphasizes the sharing and dissemination of information. Thus, there is room to consider the expansion of Magnet as a policy instrument, perhaps increasing the share of the overall R\&D support budget that it administers. There are a host of specific issues having to do with the way the Magnet program is implemented, but that is beyond the scope of this paper.

\section{How Much Support to RED?}

Is There a Basis for Setting a Policy Target? As we have seen in the subsection "Jump-Starting the Venture Capital Market" of section I, the budget of the OCS has stabilized since 1997 at a level of about $\$ 400 \mathrm{mil}-$ lion per year, following a decade of rapid growth. The high-tech sector has been lobbying for further increases, claiming that OCS grants play a key role in lowering $R \& D$ costs and hence in fueling innovation, in making Israeli companies more attractive to foreign investors, and in compensating for geopolitical disadvantages. ${ }^{48}$ The government has refused, arguing that the massive influx of venture capital and other forms of financing in recent years (primarily IPOs in Nasdaq) prove that there is hardly a need for further R\&D subsidies, and that in fact there may be room to reduce them. The result has been an impasse in policymaking towards this sector, and the concomitant uncertainty has probably had a detrimental effect on it.

Stepping out from the political economy aspects of the issue, the question is, how should we think about setting a desirable level of R\&D support? Is the current level of $\$ 400$ million appropriate, and if not, what sort of policy gradient should the government pursue? As we shall see, these questions pose serious conceptual and empirical difficulties that are well beyond the scope of this paper. Thus, we shall content ourselves just with outlining these difficulties, in the hope that they will soberly inform the policy debate and prompt further, much needed research.

The basic premise underlying the sort of neutral, across-the-board R\&D subsidies that the OCS dispenses is that, left to its own, the market will undertake too little R\&D. If so, the question of how much R\&D subsidies the government should give out amounts to asking how much of its resources a country (in this case Israel) should allocate to 
$R \& D$. If this optimal R\&D allocation exceeds the actual one, the $R \& D$ support budget should then be set so as to close the gap between them. Thus, there are two distinct problems to tackle: assessing the presumed gap between actual and optimal R\&D spending in the economy, and devising ways to bring the economy to the desired level (and perhaps mix) of R\&D spending through a subsidy program such as that of the OCS. Notice that the latter necessitates first and foremost a reliable estimate of the additionality factor.

Unfortunately, existing literature provides little guidance regarding the assessment of the gap, be it in modeling or in empirical implementation. One notable exception is Jones and William (1998): they take the social rates of return to $R \& D$ estimated in a series of studies by Griliches and others (e.g. Griliches 1994, Scherer, 1982), and use them (as well as their own estimate) in the context of a Romer (1990) growth model to derive the optimal R\&D/GDP ratio. Jones and Williams find that the U.S. devotes far too little resources to $R \& D$, and that even taking a lower bound of $30 \%$ for the social rate of return to $R \& D$, the optimal R\&D/GDP ratio may be 2 to 4 times higher than the present one of about $2.2 \%$.

It is not clear, though, whether the results of Jones and Williams and the concomitant policy implications can be readily extended to other countries. First, the optimal R\&D/GDP ratio depends critically on the ratio of the social rate of return to $R \& D$, to the economy-wide real rate of return (e.g. the long-term return on the stock market). On both accounts a country such as Israel may differ substantially from the U.S. Second, Jones and Williams consider R\&D in the context of a closed economy; in an open economy, whereby some of the benefits from an own country's R\&D spill over to other countries (see for example Coe and Helpman 1995), the notion of a "social" rate of return is far less clear.

Eaton, Gutierrez, and Kortum (1998) provide further support to the notion that countries may be underinvesting in R\&D. They laid out a detailed model of the R\&D process and of the transmission of research outcomes across countries (based on Eaton and Kortum 1996), and proceed to calibrate it for the European Union countries and to simulate its responsiveness to various policy levers. One of their conclusions is that increasing research activity in most European countries could make a substantial contribution to productivity levels not only in the E.U. but throughout the OECD. However, Eaton, Gutierrez, and Kortum stop short of endorsing the channeling of additional resources into $\mathrm{R} \& \mathrm{D}$, and they certainly do not attempt to compute an optimal 
R\&D/GDP ratio that could serve as an actual target for policy in any specific country. Still, their conclusions are congruent with a policy gradient of increasing $R \& D / G D P$ ratios, at least for most European countries.

RED Ratios as Yardsticks for Policy Much of the discussion in the literature on $R \& D$ policy is cast in terms of various $R \& D$ ratios, particularly the ratio of total civilian expenditures on R\&D to GDP (in short, R\&D/GDP). Countries compare themselves with each other in terms of these ratios, and often set targets based on averages for various reference groups (the European Union, the OECD, etc.) This is so not only because the amount of resources devoted to $R \& D$ obviously cannot be divorced from total resources available, but also because there is a great deal of uncertainty in this respect, and hence political feasibility and expedience often requires such linkages. ${ }^{49}$ Israel is no exception, and indeed Israel's standing vis-à-vis other countries in terms of $\mathrm{R} \& \mathrm{D} / \mathrm{GDP}$ ratios figures prominently in the current debate. While they surely may play a useful role in informing policymaking, we would like to argue that these ratios should be considered with great caution as yardsticks for policy, both because of measurement problems, and because of the importance of critical mass in the R\&D context.

The measurement of $R \& D$ expenditures poses serious challenges to statistical agencies, both because it is very difficult to delimit what counts as $R \& D$, and because of difficulties in computing appropriate deflators (see the appendix). Recent revisions by the Israeli Central Bureau of Statistics (CBS) of business sector R\&D (BSRD), based on an expanded definition of $R \& D$, resulted in a drastic increase in the estimates of BSRD and hence on the R\&D/GDP ratio, which have of course profound policy implications. As to $R \& D$ deflators, preliminary computations suggest that if we were to deflate by an index based on wages of R\&D personnel, the growth of BSRD would be much slower than estimated, again having serious policy repercussions.

The second problem with international comparisons of $R \& D$ ratios for policy is that of critical mass. Contrary to other areas, where the relative amount of resources may constitute a good enough yardstick (such as in health or education), what determines the effect of R\&D on the economic performance of the economy is in many cases the absolute amount invested. That is so basically because there are substantial indivisibilities in $\mathrm{R} \& \mathrm{D}$ at both the micro and macro levels. At the level of individual projects and/or firms, a wide range of technological areas require the commitment of relatively large amounts of $R \& D$ in order to 
make these projects at all feasible (in other words, the minimum efficient scale of projects in such areas is large). Thus, the development of communication satellites requires $R \& D$ budgets of hundreds of millions of dollars, and so do new pharmaceuticals.

At the economy-wide level, the conduct of $R \& D$ requires a vast array of supporting infrastructure and services, the availability of adequate manpower (not only scientists and engineers but also supporting personnel of various sorts), and of financial institutions and markets. All of these will come into being only if enough R\&D is being carried out to justify the emergence of the required infrastructure, venture capital institutions, etc. Moreover, the ability of firms conducting R\&D to capture the spillovers generated by others in the same region or country depend as well on the existence of a sufficiently large nearby R\&D sector. This latter factor can be critical for the chances of the high-tech sector in the country to become a "Silicon Valley." Thus, it is hard to compare $\mathrm{R} \& \mathrm{D} / \mathrm{GDP}$ ratios for countries that vary a great deal in size, particularly when the differences are so extreme as between the U.S. or Japan and Israel. ${ }^{50}$

Furthermore, the extent to which comparisons of R\&D ratios are informative (and potentially telling from a normative point of view) depend inter alia on the growth strategy that the countries being compared have chosen. Israel embarked long ago in a growth path that relies heavily upon the promotion of high-tech, export-oriented sectors, reflecting its perceived comparative advantage in high-skilled labor. By contrast, countries such as Spain or New Zealand, while comparable to Israel in terms of current GDP per capita, have chosen a very different path (recall section II and figure 3.4). Thus, while a R\&D/GDP ratio of about $1 \%$ for Spain might be adequate given its growth strategy, Israel's much higher ratio may still be below the mark.

In order to gain further perspective on the issue of absolute vs. relative size of expenditures in $R \& D$, consider table 3.7, where we list the leading industrial R\&D performers in the U.S., and compare them with Israel as a whole. Thus, in 1997 the absolute amount of resources allocated to civilian R\&D in Israel was $\$ 3129$ million, of which $\$ 2006$ million was in the business sector. ${ }^{51}$ That same year eight of the leading industrial R\&D performers in the U.S. spent over $\$ 2$ billion on R\&D, each of them more than Israel's industrial sector as a whole. To put it differently, all of Israel's business sector R\&D amounted to the R\&D done by Pfizer, and was slightly less than the R\&D done by Johnson and Johnson. If we took instead Israel's total civilian R\&D, that would 
Table 3.7

The 15 leading industrial R\&D companies in the U.S., and Israel R\&D expenditures, in 1997

\begin{tabular}{llcc}
\hline & & \multicolumn{2}{c}{ R\&D expenditures } \\
\cline { 3 - 4 } 1997 rank & \multicolumn{1}{c}{ Company } & R\&D (M\$) & R\&D/sales (\%) \\
\hline 1 & General Motors & 8200 & 4.9 \\
2 & Ford Motor & 6327 & 4.1 \\
3 & IBM & 4307 & 5.5 \\
Israel's total civilian R\&D & 3129 & \\
4 & Lucent Technologies & 3100 & 11.8 \\
5 & Hewlett-Packard & 3078 & 7.2 \\
6 & Motorola & 2748 & 9.2 \\
7 & Intel & 2347 & 9.4 \\
8 & Johnson \& Johnson & 2140 & 9.5 \\
Israel's business sector R\&D & 2006 & \\
9 & Pfizer & 1928 & 15.4 \\
10 & Microsoft & 1925 & 16.9 \\
11 & Boeing & 1924 & 4.2 \\
12 & Chrysler & 1700 & 2.9 \\
13 & Merck & 1684 & 7.1 \\
14 & American Home Products & 1558 & 11.0 \\
15 & General Electric & 1480 & 1.7 \\
\hline
\end{tabular}

Source: NSF science and engineering indicators - top 500 firms in R\&D by industry category, 1999. http:www.nsf.gov/sbe/srs/nsf00301.

place Israel as number 4 , just in between IBM and Lucent. These gaps are well reflected also in patent statistics (see Trajtenberg 1999): Israeli inventors were granted in 1997 a total of 653 patents, of which slightly less than half (about 320) went to Israeli corporations. By contrast, that same year IBM was granted 1758 patents, Motorola 1151, Intel 407, Hewlett-Packard 537, General Electric 667, and so forth.

\section{Prop Up Demand, or Stimulate Supply?}

As mentioned in section $I$, the basic premise underlying Israeli R\&D policy has been all along that Israel enjoys a comparative advantage in high-tech, science-based industries, because of the abundance of highly skilled labor and scientific personnel. This, coupled with the presumption that the market is likely to underinvest in R\&D, provides the rationale for the direct subsidization of industrial R\&D, as done through the OCS programs. Viewed from the vantage point of the market for 
scientists and engineers, such a policy is one that stimulates demand, implicitly assuming that supply is sufficiently elastic to provide the additional personnel called forth by the government-supported R\&D.

Figure 3.6 casts serious doubt on this set of premises ${ }^{32}$ : wages of R\&D personnel in the business sector have risen extremely fast in the second half of the 1990s, much faster than economy-wide wages (by 1999 the index of wages in R\&D had risen $54 \%$ more than all wages). Clearly, the dramatic increase in R\&D outlays by the business sector during the same period fueled the inflation in wages of $R \& D$ workers. Mirroring these developments, there is plenty of circumstantial evidence of severe shortages of computer scientists and engineers, software developers, and related personnel. The picture that emerges is thus of a very inelastic supply curve for qualified R\&D workers in recent years, which implies that any additional financial resources channeled into BSRD would achieve little increase in real R\&D in the short run, and instead would keep fueling wage inflation (see Goolsbee (1998) for a similar argument regarding the effect of government- supported R\&D in the U.S.).

Shortages of highly skilled personnel in cutting edge technologies seem to be a pervasive, worldwide phenomenon in recent years, certainly in the U.S. as well as in leading European countries. ${ }^{53}$ Romer (2000) suggests that existing institutional arrangement in the U.S. higher education system limits the supply response to these market signals, and hence necessitates corrective policy changes. In essence, the incentive system within universities is not necessarily conducive to the timely supply of graduates in fields of high demand, with regard to the number of students admitted to different fields, the mix of courses offered, the channeling of graduate students into lengthy, often dead-end postdoc positions, etc. ${ }^{54}$ Thus, Romer advocates a shift of focus in government R\&D policy, from the traditional subsidization of R\&D itself, which stimulates the demand for scientists and engineers, to programs that would directly encourage the supply of newly trained qualified manpower. In light of the trends depicted in figure 3.6, it is clear that government policy towards R\&D in Israel ought to address both sides of the market: the relative abundance of qualified manpower is no longer to be taken for granted, and there are plenty of institutional rigidities and frictions in the educational system to cast doubt on its ability to respond by itself in a timely fashion to market needs.

One specific problem in Israel, in this respect, is that there are relatively large groups of the population that have acquired significant lev- 


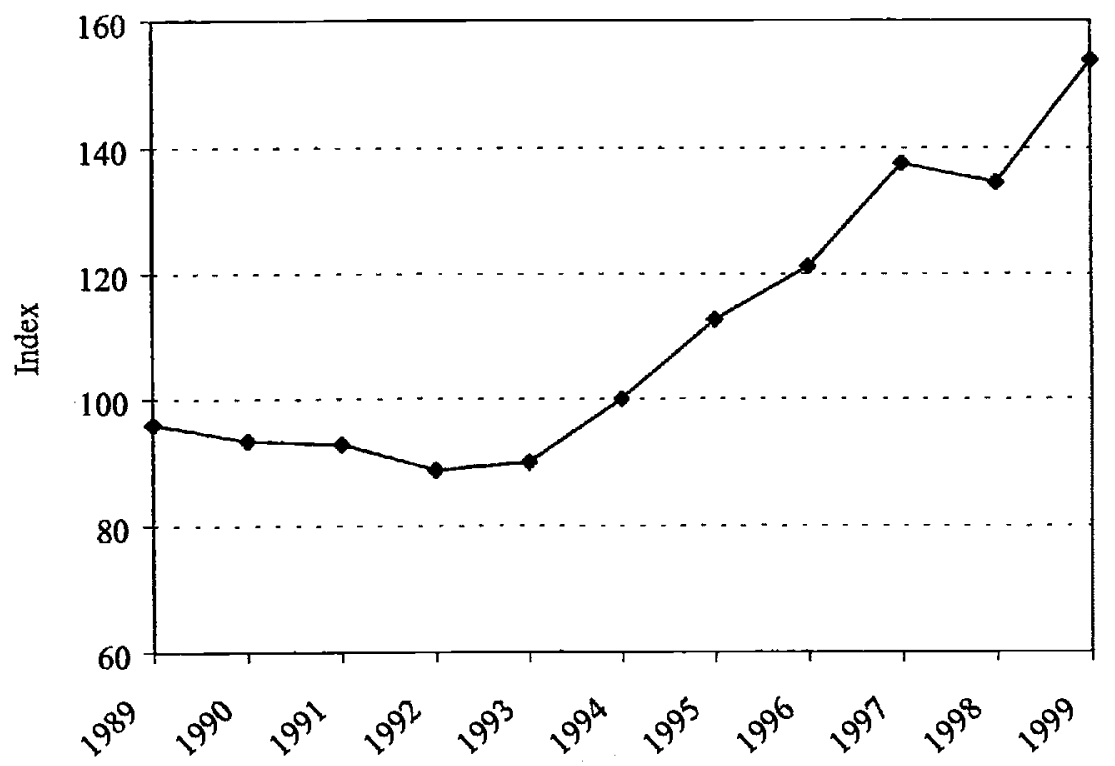

Figure 3.6

Index of wages for R\&D personnel in Israel relative to average wages (1994: 100). Source: Israeli Central Bureau of Statistics.

els of general human capital, but not the skills that are required for the high-tech sector, and that essentially do not participate in the relevant labor markets. These are primarily ultraorthodox Jews, Israeli Arabs, and residents in the "development towns" located in the geographically more distant areas. The impediments to their partaking in the job opportunities offered by the new economy are numerous, ranging from cultural barriers to geographical isolation. It is clear that tapping their potential could alleviate the shortages mentioned, and at the same time improve the economic standing of these groups. ${ }^{55}$ This would involve providing the appropriate training, setting up an institutional framework that would allow their employment in the high-tech sector without violating their cultural sensitivities, and investing in infrastructure to bring them closer to the centers of economic activity.

The case of Bangalore in India exemplifies the wide range of possibilities opened for employing skilled labor in R\&D-related activities from a distance, without the workers having to migrate and adapt to the environment of the employer. Indeed, as documented in Arora and Arunachalam (2000), a large part of the burgeoning software sector in India does subcontracting development work for U.S.-based firms. It 
would seem that a similar model could be applied within Israel for the population groups mentioned above, that is, provide them with training in situ, and employ them in their communities via subcontracting employment relationships. There seem to be a host of coordination failures that prevent that from happening without intervention, and hence there is room for the government to undertake a facilitating role.

Developments in the labor markets associated with high tech have of course wider implications. In fact, one of the most striking trends in the Israeli economy of the past two decades has been the rapid rise in pretax income inequality. Attempts by the government to keep a lid on after-tax inequality have necessitated a dramatic increase in the share of the budget (and of GDP) going to welfare, a trend that seems unsustainable. The rapid rise in the relative wages of workers in the high-tech sector has undoubtedly contributed to the growing income gap in recent years. Clearly, policies that shift up the demand for these workers would further increase inequality, at least in the short run, whereas policies that stimulate the supply response would presumably do the opposite. This is obviously a normative issue, and hence it lies well beyond the scope of this paper. However, what is becoming increasingly clear is that, as the sectors and activities associated with advanced technologies gain in importance throughout the economy, policies towards them will have to be guided by a wider set of considerations, including their distributive implications.

\section{Issues in the Design of R\&D Policies: Drawing from the Israeli Experience}

\section{How Much Total RED?}

The close-up examination of R\&D policy in Israel, and in particular the need to confront the issue of how much the government should allocate to R\&D support, brings to the surface the more fundamental problem of how much resources an economy should devote to R\&D: after all, government support is meant first and foremost to make up for the presumed underinvestment in $R \& D$ by the market, given the gap between social and private returns to $R \& D$. It is interesting to note that this issue has not received nearly as much attention as it should have, either in policy discussions or in economic research. And what a difference it could make: if for example we take at face value the findings in Jones and Williams (1998), they imply that the U.S. would have at least to double the level of resources devoted to $R \& D$ in order to approach 
anything like the optimal $R \& D / G D P$ ratio. In fact, the problem may be worse than that: as shown above for Israel, commonly used deflators for R\&D may not accurately reflect changes in the purchasing power of $R \& D$ dollars, in view of the escalating costs of $R \& D$ personnel. In the U.S. the problem is likely compounded by the fact that a significant fraction of the compensation to R\&D personnel consists of options and similar devices tied to the stock market that are hard to evaluate and translate into wage-equivalent figures.

Total R\&D in the U.S. has risen significantly in recent years, the annual number of U.S. patents granted has doubled during the decade of the 1990s (both the total and those assigned to U.S. inventors), and by any standard the high-tech sector in the U.S. has been booming. Thus, it would seem that the U.S. is devoting plenty of resources to innovation and technical change, and hence it is tempting to think that there is no reason for concern in that respect. However, "a lot" does not necessarily imply "enough," and as to R\&D/GDP ratios, it may well be that what was reasonable for the late twentieth century is no longer appropriate for the era of the Internet and the new economy. Vannevar Bush's landmark report "Science: the Endless Frontier" (1945) brought about a dramatic revision of the role of government in supporting science and technology, and a steep rise in the resources committed to R\&D. By the 1960 s a $R \& D / G N P$ ratio of about $2.9 \%$ seemed perfectly natural, and certainly not excessive, even though it constituted a doubling of that ratio from the early $1950 \mathrm{~s} .{ }^{56} \mathrm{It}$ may well be the case that a new revision is called for, but much more serious research would have to be done in order to come up with sound policy recommendations in that respect.

\section{Supply vs. Demand}

As shown in the subsection "Prop Up Demand, or Stimulate Supply?" of Section III, the wages of R\&D personnel skyrocketed in Israel, rising $50 \%$ faster than average wages, during the second half of the 1990s. This meant first and foremost that actual R\&D performed rose much more slowly than implied by the official statistics (using sectoral deflators). Second, and perhaps more importantly, wage inflation in $R \& D$ implies that the basic premise underlying the type of R\&D policy conducted in Israel might be flawed. That is, the support of the demand side (in the market for R\&D inputs, and in particular of scientists and engineers) may run into an inelastic supply schedule, leading just to wage escalation rather than to real increases in the amount of R\&D 
performed (which is the intent of the policy). Even without significant government support to the demand side, the supply elasticity may be an issue of concern for the setting of national policy in that regard, since the ability of the economy to innovate over the long run depends to a significant extent on such elasticity. Once again, the case of Israel can be seen as a laboratory where these effects are more pronounced (both the extent of support to the demand side, and the steepness of the rise in $R \& D$ wages), and hence may well constitute an early warning.

Romer (2000) examines various policy options for the U.S. in that regard, and I shall not go into them here. Let me mention two issues that I believe require further attention. As mentioned above, there are some segments of the population in Israel that have been completely bypassed by the rapid development of the high-tech sector. One of the implications is that the effective pool of workers that could feed into the rapidly advancing, $R \& D$-intensive sectors is significantly smaller than it could be if those segments were somehow incorporated in it. It would seem that something similar happens in the U.S., with respect to some minorities, immigrant groups, and geographical locations. Of course, segmentation occurs primarily along educational lines, and hence one could treat it as part of the wider problems of skill acquisition, the (in)effectiveness of the educational system, the inequalities that arise in that context, etc. What I am suggesting is that these issues have to be thought about also in the context of the elasticity of supply facing the innovative sectors of the economy, and hence in the context of R\&D policy. That is, an issue of primary interest is the availability of qualified manpower to support the rapid expansion of the high-tech sector and the structural changes that are occurring throughout the economy as information technologies are incorporated in a massive way by user sectors. All these put a great strain on the market for high-skilled workers, and the ability to keep innovating depends to a large extent on the capacity of the economy to incorporate into the pool of relevant workers wider and wider segments of the population. R\&D policies have traditionally been mostly concerned with just incentivizing and financing the demand side-a more balanced approach that also addresses the supply side is called for.

\section{Types of Support for RED}

One of the interesting features of government support programs in Israel is their variety and dynamism: since the mid-1980s, when the OCS 
was upgraded and started to operate in earnest (following the passage of the Law for the Encouragement of R\&D), there have been a series of changes that greatly expanded the menu of support programs. The core program remained the matching funds for commercial R\&D projects, but there were two important additions ${ }^{57}$ : the Incubators program and the Magnet program. Beyond the OCS's programs, the government established Yozma, the initiative to jump-start the venture capital market. The Incubators program was meant to support the very early stages of entrepreneurial, innovative projects, whereas the Magnet program was aimed at consortia of established firms with academia, targeting generic, precompetitive projects. The point is that the complex and arduous process that leads from an original idea to a successful commercial innovation may meet a series of market failures along the way, and no single program, aimed at a particular stage in that sequence, can hope to solve them all or even most of them. Moreover, the object of R\&D policy, namely innovation and innovative sectors, is by definition extremely dynamic, its structure and needs being in constant flux. Thus, R\&D policies have to respond in kind if they are to remain relevant and serve their stated purpose.

One of the interesting aspects of the Magnet program is that whereas its overt objective was to move up the ladder and support more basic R\&D (i.e. more generic projects), it is quite clear ex post that one of its main achievements may be in overcoming coordination and informational failures that turned out to be rampant. It seems that it also facilitates to a significant extent the spread of spillovers among relevant players, but that is something that requires further scrutiny. Bringing to the surface these coordination and informational problems was an important (if mostly unintended) outcome of the program, and they in turn pose a challenge to the design of further policies. The Israeli experience in this regard raises the question of the extent to which such problems are present also in the U.S., and what sort of policies may be tailored to address them.

Another important aspect of Magnet is the building of bridges between academia and industry. This has become an increasingly important issue in advanced economics, and certainly in the U.S. An interesting aspect of the Magnet model is that the connection with academia is through a consortium of firms, and not by individual firms. One advantage of this approach is that it makes it easier to preserve the independence and freedom of the academic researchers, both because there are multiple players on the other side and because the whole arrangement is open to public scrutiny. 
A further aspect of the dynamism required from the R\&D support system is the ability to recognize in real time the changing nature of the technologies to be supported. This mirrors to a large extent the need of the Patent Office to update the coverage of what is deemed patentable. A typical example is software development, which in Israel became eligible for support sometime during the $1990 \mathrm{~s}^{58}$ and the current debate on targeting biotechnology.

The case of Yozma, the government-sponsored institution that jump-started the venture capital market in Israel, is a remarkable tale of prompt and expedient government intervention that served as catalyst and marketmaker. The point here is that, even in areas that surely are better left to the market, government policy may play a (temporary and well-delimited) role in speeding up processes that might have happened by themselves, but not necessarily at the right time and/or to the extent required from a social returns point of view. There are undoubtedly positive externalities in setting up new markets (such as the venture capital market), which may lead to timing failures.

\section{Mechanisms of Support}

Once again, the Israeli experience brings to the table a whole range of issues regarding mechanisms of support to $R \& D$, for given policies, which may be relevant for the U.S. One is project selection: as mentioned above, until not long ago virtually all $R \& D$ projects that met certain threshold criteria became eligible for matching funds (which implied de facto budget accommodation), whereas in the past few years a rigid budget constraint has been forcing a switch towards explicit selection mechanisms, in view of excess demand for support.

One of the most difficult issues to confront in this context is how to preserve neutrality once a ranking system is introduced, given the difficulties in making cross-field comparisons (how would one rank, say, the top project in biotechnology vis-à-vis the top project in fiber optics?). A layered decision-making system may be called for (e.g., decide first how much to support each field, then allocate within), but then the inputs into such a system would have to be far more than just expert referee reports on individual projects. A related issue is randomization: as suggested in the sub-subsection "Allocation Schemes for the Regular OCS Program of R\&D Grants" in Section III, this may be a very attractive option, whose implementation depends to a large extent on 
political feasibility - it may well be that this is currently a more viable option in the U.S. than in Israel.

Another issue for which Israeli R\&D policy can provide an interesting case study is the payback system (to the best of my knowledge this aspect of the program is unique to Israel). Both proponents and opponents of the introduction of such a system in the U.S. can look closely at Israel's experience and learn from it. An aspect that we find particularly troubling is that of political opportunism, which clearly was at work in Israel. That is, the actual budget of R\&D support (i.e. the nominal budget minus the amount collected as paybacks) remained steady in the second half of the 1990s, and even declined slightly, but that was not a known fact: overtly the government was increasing the budget, and thus shielded itself from political pressure to increase it further.

\section{International Spillovers}

One of the most perplexing aspects of R\&D policy lies in the fact that the fruits of innovative activities do not stop at country borders, but to some extent benefit also consumers and producers in other countries. Of course, no government wants to use tax dollars to subsidize citizens from other countries. The issue is therefore one of extent, and of trade-offs: if the local benefits are very large relative to spillovers to other countries, then the support may be amply justified, but not if the benefits accrue mostly to outsiders. The main trade-off in any case is with openness and the benefits from globalization: attempts to keep the benefits at home, by somehow restricting access, are bound to impair also the inflows (in terms of trade, investment, and also technology).

Contrary to Israel, the U.S. is in the enviable position of seemingly being the recipient of substantial inflows from abroad, particularly in that there is a steady "brain gain" from other countries into the U.S., attracted by the lure of Silicon Valley, the fact that the main markets for technologically advanced products are mostly in the U.S., the availability of capital (e.g. Nasdaq), etc. At the same time, the rest of the world benefits of course from innovation in the U.S. ${ }^{59}$ R\&D policy in the U.S. should take these flows into account; thus for example, if the inflows are very substantial, there may be a multiplier effect, in that every dollar invested in R\&D in the U.S. may bring in additional innovation by attracting further innovative inputs into the country. The implications 
of such an effect for government support of R\&D could go either way, and certainly deserve further study.

\section{Concluding Remarks}

Israel constitutes an interesting laboratory case of government intervention in the realm of $R \& D$ policy. The recognized potential of the country in terms of scientific and technological prowess was leveraged by extensive government support to commercial R\&D projects, at a time when capital markets in Israel were very limited and geopolitical factors hampered the development of export-oriented industrial sectors. The principle of neutrality that governed the main support programs ensured that resources allocated responded to market signals rather than to bureaucratic directives.

The Office of the Chief Scientist proved to be very dynamic and responsive to changing circumstances, instituting from 1985 to the early 1990s a series of innovative programs that addressed emerging needs: Yozma, the government-sponsored venture capital fund that set the stage for the advent of private venture capital (and dissolved itself shortly after that started to happen on a significant scale); the Incubators program, which responded both to the opportunity opened up by the mass immigration of scientists and skilled workers from the former Soviet Union, and to the realization that a whole set of market failures might occur at earlier stages, before a firm could qualify for support from the regular OCS program; the Magnet program, designed to support generic, precompetitive, long-term projects conducted by consortia of firms and academia, and in so doing plays a role in facilitating the tapping of scientific knowledge in academia for industrial purposes, and in remedying coordination failures within industry; programs that encourage international cooperation; etc.

And indeed, available indicators show that the high-tech sector in Israel has flourished and grown remarkably quickly since the mid-1980s. Thus, the number of U.S. patents granted to Israeli inventors has more than tripled since 1985, making Israel one of the leading countries in patents per capita. Key to this impressive growth, the share of patents in computers and communications, the leading sector of the new economy has zoomed from $8 \%$ to $27 \%$ of all Israeli patents. Likewise, Israeli high-tech exports grew eightfold from 1988 to 2000 (from $\$ 1.2$ to $\$ 9.6$ billion), doubling their share of total exports to over a third. Several studies have tried to examine the extent to which government policies 
contributed to this success. Even if still tentative, available evidence suggests that they contributed significantly in various ways, including the vast expansion of capital markets, a positive effect of government grants on productivity growth, and the further stimulation of R\&D spending (additionality).

The very success of the high-tech sector, and arguably also of the underlying policies, poses new challenges that need to be addressed. The budget for support of R\&D grew in tandem with the growth of the sector, but by the late 1990s it had become sufficiently large to turn into a macro issue. Given the prevailing fiscal restraint, the government essentially froze the OCS budget, and thus brought into sharp focus the question of how to allocate these now scarce funds to a much larger pool of support applications (that qualify for support according to prevailing criteria). Options include instituting a competitive ranking system, randomization, and explicit departures from neutrality in other dimensions, such as differential support according to size of firms. Beyond allocation mechanisms, the more fundamental issue is that of setting a target $R \& D / G D P$ ratio, and deriving from it the optimal level of total R\&D support.

The rapid growth of the $R \& D$ sector eventually ran into what proved to be a highly inelastic segment of the supply of qualified manpower, inflating wages for R\&D personnel, and thus putting a cap on the actual growth of innovational efforts. Clearly, government policies will have to address both sides of the market for $R \& D$ inputs if they are to be effective. In so doing, they should consider how to bring into the realm of high tech segments of the population (and areas of the country) that so far have been left out. Further open issues include the payback provision (which risks political opportunism), the requirement of production in Israel, which may end up subsidizing inefficient local production, the extent to which support should be directed to more basic research, etc.

One way of summarizing the Israeli experience is to point out that the key to the apparent success of R\&D policies seems to have been both boldness in the deployment of resources, and flexibility and creativity (i.e. innovativeness) in responding to rapidly changing needs and challenges, many of them the product of earlier successes. Given the inherent dynamism of the high-tech sector, any policy that follows rigid rules is bound to rapidly become ineffective and/or inefficient. Thus, if the institutional setting does not allow for a speedy process of adaptation and innovation in policy design, it may be better not to 
intervene to begin with. As described in section $\mathrm{IV}$, much of this is of potential relevance for any country seeking an active role for government in the realm of advanced technology and innovation.

\section{Appendix. R\&D Figures and Ratios: Measurement Problems}

Ever since the publication and widespread adoption of the Frascati Manual in the 1980s, there has been remarkable progress in achieving international harmonization in terms of what constitutes R\&D. However, the changing nature of innovative activities poses renewed problems at every turn, as is the case for example with many types of software development and Internet-related innovations. ${ }^{60}$ Prompted by the sense that existing data collection procedures failed to take account of substantial portions of R\&D activities, the Israeli Central Bureau of Statistics (CBS) introduced in the late nineties a new and much more detailed survey of Business Sector R\&D (BSRD), which resulted in drastic revisions of previously available estimates. Thus, for example, the newly computed BSRD for 1997 was $44 \%$ higher than the previous estimate, and as a consequence the R\&D/GDP ratio jumped up by about half a percentage point to $3.1 \%$ for that year, reaching $3.5 \%$ in 1999.61

The revision that the CBS has undertaken exemplifies the difficulties of setting policy according to these ratios: until the publication of the revised figures, existing estimates indicated that Israel's R\&D/GDP was about average relative to the OECD, and moreover, that Israel's BSRD constituted a significantly smaller proportion of total R\&D than in other countries (about 50-55\%, compared to a median of $62 \%$ for the OECD). Thus, if these ratios were used as yardsticks for policy, it would have been reasonable to advocate further support to BSRD so as to increase its share, a move that would have resulted also in a moderate increase in the R\&D/GDP ratio. ${ }^{62}$ The current figures put Israel at the upper end of OECD countries in R\&D/GDP ratio, and about average in BSRD/R\&D. Thus, international comparisons of this sort would suggest at present very different policy recommendations.

The second measurement problem is that of devising appropriate deflators for $R \& D$ expenditures. The practice at the CBS has been to compute for each R\&D-performing sector an index based on the average wages in the sector on the one hand, and the costs of materials and capital outlays on the other hand (each component weighted by its appropriate share in $R \& D)$. However, a survey of wages conducted sepa- 
Table 3.8

Annual average rate of growth of BSRD: 1994-1999 (using revised figures based on new CBS survey).

In nominal Israeli shekels

Deflated by the CPI

$12 \%$

Deflated by the CBS R\&D deflator

(1994-98, prior to revision)

Deflated by new index based on wages

of R\&D personnel in business sector ${ }^{\mathrm{a}}$

aprovisional computations; approximate only.

rately by the CBS (as part of its general survey of labor and wages), indicates that wages for $R \mathcal{E} D$ personnel in the business sector rose much faster than average wages in the sector. Thus, computing a deflator based on these wages renders a very different picture, as can be seen in the comparison in table $3.8 .^{63}$

The impressive growth of BSRD in the past half decade $(12 \%$ per year, CPI-adjusted) is thus greatly attenuated on deflating it by the new and still provisional index: only about $3 \%$ per year. Of course, the $\mathrm{R} \& \mathrm{D} / \mathrm{GDP}$ ratio would be significantly lower as well if we were to compute it on the basis of these "real" magnitudes. Once again, these disparities are just meant to illustrate the extent to which the figures that might serve us as guideposts for policy are sensitive to the way we treat these measurement issues.

\section{Notes}

Prepared for the NBER conference on Innovation Policy and the Economy, Washington, April 17, 2001. I acknowledge with gratitude the support provided to this project by the Advanced Technology Program (ATP). I wish to thank Ariel Ben-Porat and Guy Michaels for research assistance; the Office of the Chief Scientist at the Ministry of Industry and Trade, Israel, for data and helpful discussions; and Adam Jaffe and Joshua Lerner for constructive comments. My warmest thanks go to Dr. Orna Berri, the former Chief Scientist, for having brought me into the realm of R\&D policy, and for the many insights that she shared with me.

1. This paper draws extensively from and constitutes a follow-up to Trajtenberg (2000).

2. See for example Klette, Moen and Griliches (1999), David and Hall (2000), and Jones and Williams (1998).

3. However, R\&D policy in Israel has virtually stalled since the late 1990 s in view of mounting challenges, and it remains to be seen whether policymaking in this area will reveal the same degree of creativity in dealing with them as it did in the past. 
4. As the title indicates, we confine ourselves to civilian, industrial R\&D. Both defense $R \& D$ and academic R\&D have played all along a pivotal role in Israel's overall research enterprise, and fueled to some extent the growth of high tech via a variety of spillovers, but these are beyond the scope of this paper.

5. We draw for this section from a variety of material from the OCS (see Israel Ministry of Industry and Trade, 1994, 1999a, 1999b, 1999c), as well as from personal involvement with the OCS, in particular with the Magnet program.

6. Actually the original payback schedule was as follows: $3 \%$ of revenues from sales of the products developed for the first 3 years, $4 \%$ in the next three years, and $5 \%$ from the seventh year onwards. This schedule has been revised a few times, and the Treasury has long been pressuring the OCS to increase these percentages, and even impose interest payments.

7. The Research Committee may grant exemptions to requirements (2) and (3), but as far as I have been able to establish, this has rarely happened.

8. In the early 1990s the 1985 law was amended so as to place the software industry on an equal footing with other industrial sectors, so that software development projects qualify for the same type of aid.

9. Israeli universities have also proved to be highly capable of generating innovations having economic potential (as manifested for example in the large number of U.S. patents assigned to them-see Trajtenberg (1999)), but once again weak links with industry have prevented the extensive exploitation of such potential.

10. "Magnet" is an acronym (in Hebrew) for "generic, precompetitive research".

11. Magnet also supports the integration of advanced technologies into industry via users' associations, but that is a secondary activity.

12. Participation is limited to Israeli-based companies and Israeli subsidiaries of foreign companies.

13. In addition to the sources already mentioned, we drew material for this section from the Internet site of the program, www.incubators.org.il.

14. Each incubator is an autonomous not-for-profit organization. Day-to-day operations are run by a professional (salaried) manager, and next to her operates a projects committee that selects and monitors the projects. These committees are composed of professionals from industry and academia, such as corporate executives, R\&D managers, and professors. Committee members volunteer their time and expertise and do not receive any financial compensation.

15. The budget for the incubator's administration is $\$ 175,000$ per year. This includes the incubator manager's salary, administrative expenses, outlays for sorting and studying of ideas, and organizational expenses for project commercialization and marketing.

16. The data come from the office of Lidia Lazens of the OCS, and were supplied by Shai Goldberg.

17. The dollar figures in tables 3.1 and 3.2 are all in current dollars; in order to transform them into constant dollars one would have to construct an appropriate R\&D deflator, of which the main component would be of course the wages of R\&D personnel (see the sub-subsection "R\&D Ratios as Yardsticks for Policy" in section III). Lacking at present a reliable deflator, and rather than using ready-made but potentially misleading price indices, we opt here to leave the figures in current dollars (a common practice is to deflate just 
by the rate of inflation in the U.S., but such a deflator is in fact irrelevant for the case at hand). Thus, all statements henceforth implying comparisons of dollar figures across time need to be qualified, since these figures are not really in the same units.

18. The projections for 2000 indicate that paybacks may have stabilized by now.

19. Startups are defined by the OCS as firms up to 3 years of age.

20. There are no official figures in that respect, but all indications are that startups have mushroomed in Israel since the mid-1990s. In fact, a recent newspaper report based on the number of startups that hired the services of accounting firms claimed that in 1999 alone 1500 new startups were formed.

21. This might also reflect a change in the technology mix of the newcomers, with more of them in Internet applications that represent novel business models rather than novel technology, and hence that may not qualify for support from the OCS.

22. Large firms are defined by the OCS as those with over $\$ 100$ million in sales; startups are firms up to 3 years of age.

23. In table 3.6 some dollar series are aggregated into 5-year totals: these sums obviously don't mean much, since the figures are in nominal dollars, but may still be useful as rough bases of comparison across firms of different sizes.

24. This figure refers to projects approved. The average number of projects applied for is about 1800 .

25. This was a deliberate policy decision by the OCS, meant to cope with the excess demand for support in view of the budget cap imposed by the Treasury.

26. A report prepared for the OCS in 1999 claimed that large firms commanded $56 \%$ of the OCS budget during the period 1985-94. If so, there is a declining trend, beyond the one-time policy shift in 1999. However, the figures are not strictly comparable, and hence we cannot assert this with certainty.

27. David, Hall, and Toole (1999) survey a body of recent empirical studies, but do not find robust patterns that could be generalized. On the other hand, using a cross-country, macroeconomic model, Guellec and Van Pottelsberghe (2000) find evidence of significant additionality effects for 17 OECD countries.

28. See also Israel CBS (1999a) for further detailed statistics on "advanced" versus traditional sectors.

29. Thus the advanced sectors include for example electronics and electrical, the mixed ones construction-related industries, and the traditional ones textiles and apparel.

30. This section consists of excerpts from Trajtenberg (1999).

31. The in-between flat period of 1987-91 (which represents R\&D activity done circa 1985-89) presumably reflects the big macro adjustment and micro restructuring that followed the stabilization program of 1985.

32. The R\&D figures are from Griliches and Regev (1999, table 1). Since these refer to industrial $R \& D$, it may be more appropriate to relate them to Israeli corporate patents than to total patents. In practice the two patent series move pretty much in tandem, and hence the correlations with R\&D of either series are virtually the same.

33. Patent applications reflect (successful) R\&D conducted prior to the filing date, with lags varying by sector. Thus, the number of patents in a particular year should be 
attributed to investments in R\&D carried out in the previous 1-2 years at least, and in some sectors further back.

34. The reference group was chosen according to their GDP per capita in the early 1990s, that is, we chose the four countries that had at that time a level of GDP per capita closest to that of Israel (in purchasing power parity terms). Notice that, except for Spain, the countries in this group are also very similar to Israel in population.

35. Another normalization of interest would be R\&D expenditures, but except for the G7, the figures are far from satisfactory.

36. As mentioned in the introduction, a great deal of research on R\&D policy has been done recently. Aside from the references mentioned there, see also David, Hall, and Toole (1999), Hunt and Tybout (1998), and Klette and Moen (1998a, 1998b).

37. Apparently this was the first time in the history of the OCS that demand exceeded the budget provision by a substantial amount.

38. Indeed, in January 2000 the government initiated a move aimed at revising the R\&D Law.

39. Some projections indicate that would be true even if the budget were increased substantially.

40. It is quite likely that the present system in actuality is not neutral either, but the lack of neutrality is disguised. In a ranking system the issue rises to the surface and will have to be addressed head on.

41. It is interesting to note that there is a great deal of interest in this policy both in the U.S. and in Europe, and it would seem that at some point some version of randomization will be implemented. One of the great advantages (in the long run) of such a policy is that it allows for methodologically sound assessment studies of the efficacy of government support (since the control sample is built-in).

42. In fact, it would seem that, while formally neutral, actual support policies favored particular technological areas, primarily electronics, and (until the mid-1990s) large firms over smaller ones (see below).

43. Except for the Incubators program, as described in Section II.

44. By startups we mean young, small ongoing firms, not those that are still in the incubator phase.

45. The percentage was set at $3 \%$, but there have been several attempts by the Treasury to raise it further (to $4.5 \%$ ), and even to charge interest on the principal. In fact, the Treasury has been promoting the idea that the grants should turn into conditional loans, which will serve as a way of overcoming financial constraints on $R \& D$ firms, but not as a straight R\&D subsidy.

46. Consider that the OCS has dealt with R\&D projects of about 3000 firms in the past 15 years, and keep in mind that, as said before, the whole business sector R\&D of Israel amounts to that done by the 8 th largest R\&D spender in the U.S., Johnson and Johnson (see table 3.7).

47. I was a member of the Board of Directors of Magnet, and in that capacity I have witnessed many times this sort of failure, not only between firms but also between firms and academia. One of the most striking was the case of the digital printing consortium: the main players involved were unaware until the formation of the consortium of crucial re- 
search on properties of ink that was being conducted at some academic institutions in Israel (virtually next door).

48. The high-tech sector is actually split in this respect: on the one hand the traditional electronics sector demands bigger budgets for the OCS; on the other hand, Internetrelated ventures and some of the new software developers lobby instead for favorable tax breaks, particularly with regard to capital gains.

49. Thus, advocating a move towards the mean R\&D/GDP ratio of a "relevant" group of countries is politically easier to justify than persistent divergence from such reference ratios.

50. If one could compute an optimal $R \& D / G D P$ ratio for different countries, chances are that it would be a concave, decreasing function of size.

51. These figures are based on the revised estimates produced by the CBS on the basis of its new survey. The previous estimates placed Israel much lower on that scale: 16th in BSRD, and 7th in total R\&D.

52. All this refers to developments up until the last quarter of 2000: the economic downturn that started then may have temporary halted or perhaps even reversed some of these trends.

53. One of the related, hotly debated policy issues in many countries is the extent to which foreign high-tech workers should be allowed in. This has also become a highly controversial issue in Israel.

54. Romer's view would seem to contradict Rosenberg's $(1999,2000)$, who has persuasively argued that one of the key sources of strength underlying the technological and scientific prowess of the U.S. has been the responsiveness of universities to market needs and new technological developments. However, it could well be that what had characterized universities throughout most of the twentieth century does not quite hold in recent years, and/or that the pace of change has accelerated, and hence the response of universities seems more sluggish now.

55. These are mostly in the lowest income brackets, and account for a large fraction of the unemployed.

56. See Mowery and Rosenberg (1989, table 6.2, p. 127): the R\&D/GNP ratio was 1.4 in 1953, and climbed rapidly to about 2.9 in the mid-1960s.

57. There were other changes and additions, but these two constitute the most dramatic expansion of the policy menu.

58. We could not ascertain exactly when that happened, but it surely was before the late 1990s.

59. See Coe and Helpman (1995), and Bayoumi, Coe, and Helpman (1999): they show that productivity growth in other countries is an increasing function of the R\&D done in the U.S., mediated by trade flows. Such cross-influences exist for most advanced countries, but the sheer size of U.S. R\&D is such that it becomes a dominant factor for many other countries.

60. Regarding the Internet, it is often hard to distinguish between developments that are purely the result of entrepreneurship and those that are the outcome of $R \& D$ as traditionally defined. 
61. These are the latest (and still preliminary) ratios computed by CBS for international comparisons. Israel CBS (1999b) reports a R\&D/GDP ratio of 2.3 for 1996, the latest such official figure there. The revisions put the figure for that year at 2.8 , so the increase in the ratio due to the new survey is at least half a percentage point.

62. See for example an earlier version of this paper, Trajtenberg (2000).

63. We inflated the old 1996 figure by a factor of 1.44 (recall that the new estimate for BSRD 1997 was $44 \%$ higher than the previous one) in order to compute the rate of change for 1996-97. From then on we used the new figures.

\section{References}

Arora, Ashish, and V. S. Arunachalam. 2000 "The Globalization of Software: The Case of the Indian Software Industry." Report submitted to the Sloan Foundation, Carnegie Mellon University.

Bayoumi, Tamim, David T. Coe, and Elhanan Helpman. 1999. "R\&D Spillovers and Global Growth." Joumal of International Economics 47(2): 399-428.

Bregman, A., M. Fuss, and H. Regev. 1991. "High Tech and Productivity: Evidence from Israeli Industrial Firms." European Economic Review 35: 1199-1221.

Bregman, A., and A. Merom. 1998, February. "Productivity and Its Causes in Israeli Industry, 1960-1996." Discussion Paper Series 98.03. Bank of Israel, Research Department.

Busom, Isabel. 2000. "An Empirical Evaluation of the Effects of R\&D Subsidies." Economics of Innovation and New Technology. Vol. 9(2), pp. 118-48

Coe, David T., and Helpman, Elhanan. 1995. "International R\&D Spillovers." European Economic Review 39(5): 859-87.

David, P. A., and B. Hall. 2000, February. "Heart of Darkness: Modeling Public-Private Funding Interactions Inside the R\&D Black Box." Working Paper no. W753. Cambridge, MA: National Bureau of Economic Research.

David, Paul, Bronwyn Hall, and Andre A. Toole. 1999, October. "Is Public R\&D a Complement or a Substitute for Private R\&D? A Review of the Econometric Evidence." Working Paper no. 7373. Cambridge, MA: National Bureau of Economic Research.

Eaton, Jonathan, Eva Gutierrez, and Samuel Kortum. 1998. "European Technology Policy: Research Efforts in Europe Matter." Economic Policy 27: 403-30.

Eaton, Jonathan, and Samuel Kortum. 1996. "Trade in Ideas: Patenting and Productivity in the OCED." Journal of International Economics 40: 251-278.

Feldman, Maryann P., and Maryellen R. Kelley. 2000. "Winning an Award from the Advanced Technology Program: Economic Potential, Quality, and Risk." Advanced Technology Program, NIST. Forthcoming.

Goolsbee, Austan. 1998. "Does Government R\&D Policy Mainly Benefit Scientists and Engineers?" American Economic Review 88(2): 298-302.

Griliches, Zvi. 1994. "Productivity, R\&D, and the Data Constraint." American Economic Review 84: 1-23.

Griliches, Z., and H. Regev. 1995. "Firm Productivity in Israeli Industry 1979-1988." Journal of Econometrics 65: 175-203. 
Griliches, Zvi, and Haim Regev. 1999, November. "R\&D, Government Support and Productivity in Manufacturing in Israel, 1975-94" (in Hebrew). The Economic Quarterly 46: 335-336.

Guellec, Dominique, and Bruno van Pottelsberghe. 2000. "The Impact of Public R\&D Expenditure on Business R\&D." STI Working Paper no. 2000/4. Paris: Organization for Economic Cooperation and Development.

Hunt, J., and J. Tybout. 1998, March. "Does Promoting High Tech Products Spur Development?" Mimeo. World Bank.

Israel Central Bureau of Statistics (CBS). 1999a, August. "Survey of Structure of Labor Force, Patterns of Work and Innovation in Manufacturing-1997." Jerusalem: CBS.

Israel Central Bureau of Statistics (CBS). 1999b, October. "National Expenditure on Civilian Research and Development 1989-1998." Publication no. 1121. Jerusalem: CBS.

Israel Ministry of Industry and Trade, Office of the Chief Scientist (OCS). 1994. "Israeli Innovations and Technologies 1994." Jerusalem: OCS.

Israel Ministry of Industry and Trade, Office of the Chief Scientist (OCS). 1999a, September. "Encouragement of Industrial R\&D in Israel." Jerusalem: OCS.

Israel Ministry of Industry and Trade, Office of the Chief Scientist (OCS). 1999b. "Magnet Program 1998-Drawing Potential for Progress." Jerusalem: OCS.

Israel Ministry of Industry and Trade, Office of the Chief Scientist (OCS). 1999c. "Start-ups \& Innovations-A Guide to Israeli Start-ups and High-Tech Projects." Jerusalem: OCS.

Jones, C. I., and J. C. Williams. 1998, November. "Measuring the Social Returns to R\&D." Quarterly Journal of Economics: Vol 13, no 114: 1119-1135.

Klette, T. J., and J. Moen. 1998a, April. "From Growth Theory to Technology Policy-Coordination Problems in Theory and Practice." Discussion Paper no. 219. Statistics Norway, Research Department.

Klette, T. J., and J. Moen. 1998b, June. "R\&D Investment Responses to R\&D Subsidies: A Theoretical Analysis and a Microeconometric Study." Mimeo. Oslo.

Klette, T. J., and J. Moen. 1999. "From New Growth Theory to Technology Policy-Coordination Problems in Theory and Practice." Nordic Journal of Political Economy 25: 53-74.

Klette, T. J., J. Moen, and Z. Griliches. 2000. Do Subsidies to Commercial R\&D Reduce Market Failures-Some Microeconometric Studies." Research Policy (Special issue on "The Economics of Technology Policy") 29: 471-495.

Lach, Shaul. 2000, June. "Do R\&D Subsidies Stimulate or Displace Private R\&D? Evidence from Israel." Mimeo. Hebrew University of Jerusalem.

Michlol Consultancy. 1999, April. "Research on the Contributions of the OCS-Final Report." Unpublished mimeo.

Mowery, David, and Nathan Rosenberg. 1989. Technology and the Pursuit of Economic Growth. Cambridge, U.K.: Cambridge University Press.

Organization for Economic Cooperation and Development. 1993. Frascati Manual: The Measurement of Scientific and Technical Activities: Standard Practice for Surveys of Research and Experimental Development. 
Romer, Paul M. 1990, October. "Endogenous Technological Change." Journal of Political Economy 98: S71-S102.

Romer, Paul. 2000, June. "Should the Government Subsidize Supply or Demand for Scientists and Engineers.". Working Paper no. 7723. Cambridge, MA: National Bureau of Economic Research.

Rosenberg, Nathan. 1999. "American Universities as Endogenous Institutions." Mimeo. Department of Economics, Stanford University.

Rosenberg, Nathan. 2001. "America's University/Industry Interfaces, 1945-2000." In Gunnar Törnqvist and Sverker Sörlin, eds., The Wealth of Knowledge. Universities in the New Economy.

Scherer, Frederic M. 1982. "Inter-industry Technology Flows and Productivity Growth." Review of Economic and Statistics 64: 627-634.

Teubal, Morris. 1999, November. "Towards an R\&D Strategy for Israel" (in Hebrew). The Economic Quarterly 46: 359-383.

Toren, Benny. 1990. "R\&D in Industry." In D. Brodet, M. Justman, and M. Teubal, eds., Industrial Technological Policy for Israel. The Jerusalem Institute for Israeli Studies.

Trajtenberg, Manuel. 2001, March. "Innovation in Israel 1968-97: A Comparative Analysis Using Patent Data." Research Policy 30(3): 363-390.

Trajtenberg, Manuel. 2000, October. "R\&D Policy in Israel: An Overview and Reassessment." Working Paper no. 7930. Cambridge, MA: National Bureau of Economic Research.

Wallsten, Scott J. 2000. "The Effects of Government-Industry R\&D Programs on Private R\&D: The Case of the Small Business Innovation Research Program." Rand Journal of Economics 31(1): 82-100. 